Check for updates

Cite this: RSC Adv., 2018, 8, 40426

Received 11th October 2018

Accepted 26th November 2018

DOI: $10.1039 / c 8 r a 08435 a$

rsc.li/rsc-advances

\section{Quantum curcumin mediated inhibition of gingipains and mixed-biofilm of Porphyromonas gingivalis causing chronic periodontitis $\nmid$}

\author{
Ashish Kumar Singh, ${ }^{\text {ab }}$ Shivangi Yadav, ${ }^{a}$ Kavanjali Sharma, ${ }^{c}$ Zeba Firdaus, ${ }^{d}$ \\ Prerana Aditi, ${ }^{d}$ Kaushik Neogi, ${ }^{e}$ Monika Bansal, ${ }^{f}$ Munesh Kumar Gupta, ${ }^{a}$ \\ Asheesh Shanker, ${ }^{9}$ Rakesh Kumar Singh ${ }^{\mathrm{b}}$ and Pradyot Prakash (DD *a
}

\begin{abstract}
Periodontitis is a biofilm-associated irreversible inflammation of the periodontal tissues. Reports suggest the role of Porphyromonas gingivalis specific Arg- and Lys-specific proteinases in the orchestration of the initiation and progression of periodontal diseases. These proteinases are precisely termed as gingipains $\mathrm{R}$ and $\mathrm{K}$. Curcumin is an active polyphenol that is extracted from the rhizomes of Curcuma longa. However, the molecule curcumin owing to its high hydropathy index and poor stability has not been able to justify its role as frontline drug modality in the treatment of infectious and non-infectious diseases as claimed by several investigators. In the present study, at first, we synthesized and characterized quantum curcumin, and investigated its biocompatibility. This was subsequently followed by the evaluation of the role of quantum curcumin as an antimicrobial, anti-gingipains and antibiofilm agent against Porphyromonas gingivalis and select reference strains. We have successfully synthesized the quantum curcumin utilizing a top-down approach with the average size of $3.5 \mathrm{~nm}$. Apart from its potent antimicrobial as well as antibiofilm properties, it also significantly inhibited the gingipains in a dose-dependent manner. At the minimal concentration of $17.826 \mu \mathrm{M}$, inhibition up to $98.7 \%$ and $89.4 \%$ was noted for gingipain $\mathrm{R}$ and $\mathrm{K}$ respectively. The data was also supported by the in silico docking experiments which revealed high exothermic enthalpies $\left(-7.01\right.$ and $\left.-7.02 \mathrm{cal} \mathrm{mol}^{-1}\right)$. Besides, the inhibition constant was found to be $7.24 \mu \mathrm{M}$ and $7.1 \mu \mathrm{M}$ against gingipains $\mathrm{R}$ and $\mathrm{K}$ respectively. The results suggest that quantum curcumin is a potential drug candidate which needs further clinical validation.
\end{abstract}

\section{Introduction}

Periodontitis is a biofilm-associated inflammatory disease of the gingiva and the supporting structures of the periodontium (gingival, alveolar bone, periodontal ligament, and cementum) which has multiple etiologies; however, microbial and

${ }^{a}$ Bacterial Biofilm and Drug Resistance Research Laboratory, Department of Microbiology, Institute of Medical Sciences, Banaras Hindu University, Varanasi 221005, India. E-mail: pradyot_micro@bhu.ac.in

${ }^{b}$ Molecular Immunology Laboratory, Department of Biochemistry, Institute of Science, Banaras Hindu University, Varanasi 221005, India

${ }^{c}$ Department of Pathology, Institute of Medical Sciences, Banaras Hindu University, Varanasi 221005, India

${ }^{d}$ Department of Medicinal Chemistry, Institute of Medical Sciences, Banaras Hindu University, Varanasi 221005, India

${ }^{e}$ Department of Pharmaceutical Engineering and Technology, Indian Institute of Technology, Banaras Hindu University, Varanasi 221005, India

${ }^{f}$ Faculty of Dental Sciences, Institute of Medical Science, Banaras Hindu University, Varanasi 221005, India

${ }^{g}$ Department of Bioinformatics, Central University of South Bihar, Gaya 824236, Bihar, India

$\dagger$ Electronic supplementary information (ESI) available. See DOI: $10.1039 / \mathrm{c} 8 \mathrm{ra0} 8435 \mathrm{a}$ immunological factors are reported to be pivotal. ${ }^{1,2}$ More precisely, periodontitis insinuates the plaque-induced irreversible inflammation of the periodontal tissues which ultimately obliterates the periodontal ligament and alveolar bone. ${ }^{3}$ An estimate from World Health Organization reveals $10-15 \%$ global load of this disease among total adult population. ${ }^{4}$ Plaque is an established biofilm which exemplifies the socialization wherein mixed consortia of bacteria co-exist which in turn determines the biofilm matrix composition and mutual cooperativity ${ }^{1,5}$ After microbial inhabitation, the immune system comes into play and the disease is aggravated further by the destructive host inflammatory responses. ${ }^{6-9}$ However, reports suggest the involvement of only a few sorts of bacteria inhabiting the subgingival niche which orchestrate the initiation and progression of periodontal disease. ${ }^{10}$ In this context, Porphyromonas gingivalis, a Gram-negative anaerobe becomes especially important because of its diverse armamentarium both structural and functional, needed for its success (pathogenesis and progression of the inflammatory events) in the said microenvironment. It seems to be the keystone species in the development of chronic periodontitis. ${ }^{3,11}$ Datta et al. reported this bacterium in $85.75 \%$ of subgingival plaque samples from 
patients with chronic periodontitis. ${ }^{12}$ Surprisingly, for its survival, this bacterium depends on the fermentation of amino acids for energy in deep periodontal pockets where sugar availability is scarce. ${ }^{13}$ A plethora of literature document the essentiality of exceedingly high concentrations of cysteine proteinases with trypsin-like activities in the adult-onset periodontitis. ${ }^{6,11,13-16}$ Besides, to initiate and prolong the inflammatory response during periodontitis, a number of biochemical cascades are needed which require proteolytic activities. As per the report of de Diego et al., gingipain $\mathrm{R}$ and $\mathrm{K}$ collectively account for $85 \%$ of the extracellular proteolytic activity of $P$. gingivalis at the site of infection. ${ }^{17}$ Gingipains orchestrate diverse functions, which aid in bacterial survival. It activates kallikrein/kinin cascade, inactivates host proteinase inhibitors, foster dysregulation of coagulation and complement cascade, degrades immunoglobulins, bactericidal proteins, Fetransporting proteins $e t c .^{3,14-16}$

The routine therapeutic modality for periodontitis management is scaling and root planing (SRP) wherein supra and subgingival plaque and calculus are removed. ${ }^{18}$ However, the recalcitrance of biofilm dwellers and recolonization at the treated sites cannot be overruled. ${ }^{19}$ Possibly, owing to this, now a day's application of nonspecific broad-spectrum antibiotics locally at sites are in vogue as an addendum to the mechanical debridement. Drugs like chlorhexidine, delmopinol, tetracycline, minocycline, doxycycline, metronidazole etc. in the form of mouthwash etc. are routinely used to curb the re-proliferation of periodontopathic bacteria following SRP. ${ }^{20}$ However, the poor effectiveness of these drugs against the plaque biofilms and bacterial stochastic variations demands new effective measures for its management. The lack of selectivity of these drugs further complicates the situation by affecting the beneficial commensals as well as impart undesired side effects such as vomiting, diarrhea, addiction, or teeth discoloration..$^{18,20-22}$

The therapeutic inadequacies of the drugs are due to the lack of selectivity and upsurge of antimicrobial resistance within the plaque biofilms. ${ }^{20}$ The situation becomes more complex when microbial shifting occurs during the course of biofilm development, especially during plaque formation and maturation. ${ }^{5} \mathrm{~A}$ report by Marsh et al. has indicated the role of dysbiosis in the oral cavity that leads to periodontitis. ${ }^{23} \mathrm{~A}$ recent report by Dewhirst $e t$ al. suggested the presence of over 700 bacterial species in the oral cavity. ${ }^{21}$ Interestingly, early bacterial colonizers in the oral cavity are reported to actively recruit other bacteria as well. For instance, Streptococcus gordonii was found to promote and help establish the biofilm of Porphyromonas gingivalis via several genetic mechanisms. ${ }^{13}$ As periodontitis develops, the oral microbiota shifts from the one consisting largely of Gram-positive aerobes to one consisting predominantly of Gram-negative anaerobes. This cooperative recruitment of metabolically and phylogenetically diverse bacteria leads to the overall functional heterogeneity which confers several advantages like metabolic cooperation, wherein the waste of one bacterial species serves as the food for the other. ${ }^{5}$ One noteworthy illustration is the fermentation of sugars to lactic acid by Streptococci which is then disintegrated to propionate and acetate by Veillonella spp..$^{5}$ Furthermore, bacterial cross-talk in the form of quorum sensing help them to regulate their social behaviour. Reports suggest that the oral bacteria produce and respond to the autoinducer-2 signaling. ${ }^{24}$ These all conducive underpinnings further tunes the matrix chemistry for their survival, ultimately influencing the therapeutic outcomes. Therefore, it becomes prudent for the scientific community to look for easily available, cost-effective therapeutic agent(s) having both antimicrobial and anti-biofilm activities with no or minimal side-effects or toxicity.

Etiology suggests that the periodontitis can only be successfully tackled after simultaneously addressing the bacterial and inflammatory components responsible for the condition. Curcumin fits in our requirement window. A plethora of literature documents the anti-inflammatory, antioxidant, anticancer, antibacterial and anti-fungal properties of curcumin, a hydrophobic curcuminoid, extracted from the rhizomes of Curcuma longa. ${ }^{25,26}$ Curcumin was found to be highly effective against a wide array of microbial pathogens ranging from Trichomonas vaginalis, Helicobacter pylori to Candida albicans and Paracoccidioides brasiliensis. ${ }^{26-29}$ Besides, it was also reported to inhibit the biofilm formation by Escherichia coli, Pseudomonas aeruginosa, Klebsiella pneumonia, Staphylococcus aureus, and Staphylococcus epidermidis. ${ }^{25}$ Among the oral bacteria, curcumin was reported to inhibit sortase A of Streptococcus mutans, a major cariogenic bacteria. ${ }^{30}$

The scientific literature is inundated with the reports pertaining to the determination of minimum inhibitory concentration (MIC) of curcumin against various pathogens. ${ }^{31-34}$ However, we faced difficulties in determining and interpreting the results due to its insolubility and instability. These factors resulted in the colored precipitation which obscured the precise and accurate MIC determination as per CLSI guidelines. Therefore, as a drug, the use of curcumin is limited due to several such constraints. Nevertheless, attempts have been made to increase its aqueous solubility and bioavailability by the nanoparticle-based approach. ${ }^{33}$ For this, liposomes, polymeric nanoparticles, and recently lipid-drug hybrid nanoparticles have been extensively studied, where they have shown improved efficacies. ${ }^{35-38}$ Nonetheless, the innate toxicity issues cannot be overlooked. Recently, the newer quantum approach has also been utilized for its stability, solubility and therapeutic potential by making quantum curcumin against aerobic pathogens. However, its detailed toxicity evaluation is yet to be done. $^{25}$

In the present work, we synthesized, characterized and then evaluated the antimicrobial and antibiofilm potential of CurQDs against representative periodontic bacterium Porphyromonas gingivalis along with other facilitating bacteria like Actinomycetemcomitans viscosus and Streptococcus mutans. Moreover, degradative effects of CurQDs on $P$. gingivalis and on mixed $P$. gingivalis-S. mutans $-A$. viscosus biofilm formation were also examined. Furthermore, we tried to elucidate the action of quantum curcumin against the most significant virulence factor of anaerobe Porphyromonas gingivalis: gingipain $\mathrm{R}$ and $\mathrm{K}$ which was further validated by docking experiments. These studies were made after the detailed investigations pertaining to the biocompatibility of quantum curcumin which included in vitro 
cell viability assay by methylthiazoltetrazolium salt, haemocompatibility assay, membrane integrity assay using lactate dehydrogenase as marker and investigation of the production of reactive oxygen species (ROS) using flow cytometry.

\section{Materials and methods}

\section{Chemicals}

Curcumin ( $>95 \%$ pure) was procured from TCI chemicals, Japan. Phosphate Buffered Saline (PBS, $\mathrm{pH}$ 7.2), Tris-HCl buffer (pH 7.6) were prepared in-house while Dulbecco's modified Eagle's medium, DABCO and propidium iodide from Life technologies, Invitrogen were used. Flat-bottom polystyrene 96well tissue culture plates and 8-well chambered slides were procured from SPL biosciences, Korea. Penicillin, streptomycin and gentamicin were from SRL laboratories, India while iodonitrotetrazolium chloride, Hanks balanced salt solution (HBSS), heparin, sodium bicarbonate, dimethylsulphoxide (DMSO), benzoyl-L-arginine-4-methylcoumaryl-7-amide, $\quad t$-butyl-oxycarbonyl-L-valyl-L-leucyl-L-lysine-4-methylcoumaryl-7-amide, $N_{\alpha^{-}}$ p-tosyl-L-lysine chloromethyl ketone hydrochloride, and methylthiazoltetrazolium salt were from Sigma-Aldrich, USA. Trisodium citrate, calcium chloride $\left(\mathrm{CaCl}_{2}\right)$, sodium chloride $(\mathrm{NaCl})$, crystal violet (CV), dimethyl sulfoxide (DMSO) and acetone were procured from Merck, USA while paraformaldehyde, brain heart infusion (BHI) broth, Colombia blood agar, yeast extract, hemin, menadione, cysteine, and fetal bovine serum were procured from HiMedia laboratories, Mumbai.

\section{Synthesis of quantum curcumin (CurQDs)}

The synthesis of CurQDs was hierarchical and was done by the two-step top-down method as described earlier with modifications. ${ }^{25}$ Initially, a stock solution of $20 \mathrm{mM}$ curcumin was prepared in DMSO. A stock solution of $150 \mathrm{mM}$ trisodium citrate was also prepared in deionized water. CurQDs formation was investigated using different concentrations curcumin $0.125 \mathrm{mM}$ to $2.5 \mathrm{mM}$ at different $\mathrm{pH}$ ranging from 4 to 7 . In a typical experiment, $0.1 \mathrm{mM}$ of curcumin was taken in deionized water and its $\mathrm{pH}$ adjusted using trisodium citrate. Further, $2.5 \mathrm{~g}$ of zirconia beads $(0.1 \mathrm{~mm}$ in diameter) were put in the $50 \mathrm{ml}$ oak ridge tube and spun at $2500 \mathrm{rpm}$ for $15 \mathrm{~min}$ with the progressive increase in the drug loading up to $2.5 \mathrm{mM}$. The resultant solution was siphoned out and dried using rotary evaporator at $70{ }^{\circ} \mathrm{C}$. From this, a stock solution of $1 \mathrm{mM}$ was prepared in acetone which was then added dropwise to hot water $(25 \mathrm{ml})$ at $75 \pm 5{ }^{\circ} \mathrm{C}$ at the rate of $0.2 \mathrm{ml} \mathrm{min}^{-1}$ with continuous ultra-sonication for about an hour with power input of $750 \mathrm{~W}$, frequency $20 \mathrm{kHz}$, and intensity $30 \mathrm{~W} \mathrm{~cm}^{-2}$.

The final solution was kept at room temperature for $48 \mathrm{~h}$ and centrifuged at a speed of $10000 \mathrm{rpm}$ for $15 \mathrm{~min}$ at $4{ }^{\circ} \mathrm{C}$ to remove any residual native curcumin if present. The suspension was finally dried and re-suspended in deionized water and used for further characterizations. For XRD and Raman spectroscopic measurements, the isolated quantum curcumin were freeze-dried to obtain a dry powder.

\section{Physical characterization}

The prepared quantum curcumin was monitored spectroscopically at a wavelength range of $300-700 \mathrm{~nm}$. All the absorbance and fluorescence readings were made in Lambda $25 \mathrm{UV}$-visible spectrometer, Perkin Elmer and LS fluorescence spectrophotometer Perkin Elmer. Morphological features of quantum curcumin were analyzed by electron microscopy. A drop of the sample was allowed to dry on carbon-coated copper grids in the air. For TEM analysis, the images were acquired through FEI Tecnai 200 TEM operated at $80 \mathrm{kV}$ and high-resolution images in Tecnai transmission electron microscope at $300 \mathrm{kV}$. The phase compositions and crystalline nature of CurQDs were further studied by XRD in Rigaku MINIFLEX 600, Japan using $\mathrm{Cu}$ radiation at $k=0.1546 \mathrm{~nm}$ at a voltage of $40 \mathrm{kV}$ and a current of $30 \mathrm{~mA}$. Additionally, surface composition of the synthesized quantum curcumin was investigated by high-resolution X-ray photoelectron spectroscopy. Besides, Raman spectroscopy was also used to assess the phase variability and structure. The Raman spectrum was obtained on Renishaw In-Via Raman spectrometer using $50 \times$ objective from Lica. The sample was excited by $532 \mathrm{~nm}$ solid state diode laser and acquisition time for each window was selected as $50 \mathrm{~s}$. The zeta potential of CurQDs was measured on Delsa Nano (Beckman-coulter, United Kingdom) utilizing zeta dip cells. For the measurement, the sample was prepared by mixing CurQDs in $10 \mathrm{mM}$ $\mathrm{NaCl}$ in $1: 10$ proportion and then $1 \mathrm{ml}$ of the diluted sample was used.

\section{Chemical characterization}

Nuclear magnetic resonance spectroscopy. The nuclear magnetic resonance analysis $\left({ }^{1} \mathrm{H}\right.$ NMR and $\left.{ }^{13} \mathrm{C} N M R\right)$ was carried out using JEOL spectrometer at $300 \mathrm{~K}$ at $500.13 \mathrm{MHz}$ equipped with $5 \mathrm{~mm}$ broadband probe, using dried quantum curcumin dissolved in $600 \mu \mathrm{l}$ DMSO- $\mathrm{d}_{6} \cdot{ }^{1} \mathrm{H}$ NMR measurements were made at $300 \mathrm{~K}$, and the chemical shifts (ppm) were assigned. The spectral width was $10330.578 \mathrm{~Hz}$, and the digital resolution was $0.157 \mathrm{~Hz}$, with an acquisition time of $3.17 \mathrm{~s}$. A total of 16 scans were taken. ${ }^{13} \mathrm{C}$ NMR measurements were done at $300 \mathrm{~K}$ at $500.13 \mathrm{MHz}$, and the chemical shifts (ppm) were assigned. The spectral width was $26455.02 \mathrm{~Hz}$ with the digital resolution of $1.61 \mathrm{~Hz}$ and acquisition time of $0.30 \mathrm{~s}$. The spectrum was obtained with 1024 scans.

\section{Toxicity profiling of quantum curcumin}

Cell culture and treatment conditions. Vero cells (kidney cell line) were cultured in Dulbecco's modified Eagle's medium supplemented with $10 \%$ fetal bovine serum along with $100 \mathrm{U}$ $\mathrm{ml}^{-1}$ penicillin and $100 \mathrm{mg} \mathrm{ml}{ }^{-1}$ streptomycin in a $5 \% \mathrm{CO}_{2}$ humidified atmosphere at $37{ }^{\circ} \mathrm{C}$ in a $\mathrm{CO}_{2}$ incubator. A $1 \mathrm{M}$ solution of quantum curcumin was prepared as extricated above and was stored as small aliquots at $4{ }^{\circ} \mathrm{C}$ and diluted two folds in a different dose ranging from 10-70 $\mu \mathrm{M}$ in Dulbecco's modified Eagle's medium. The cells were exposed to CurQDs for $24 \mathrm{~h}$. 


\section{MTT assay for in vitro cell viability assay}

Methylthiazoltetrazolium bromide (MTT) assay was carried out to evaluate the cell viability. Briefly, Vero cells were seeded in 96well plate at a density of $1 \times 10^{4}$ cells per well in a final volume of $150 \mu$ l Dulbecco's modified Eagle's medium and incubated with various concentrations of quantum curcumin and $\mathrm{MoS}_{2}$ QDs $(10 \mu \mathrm{M}, 20 \mu \mathrm{M}, 30 \mu \mathrm{M}, 40 \mu \mathrm{M}, 50 \mu \mathrm{M}, 60 \mu \mathrm{M}$, and $70 \mu \mathrm{M})$ at $37^{\circ} \mathrm{C}$ for $24 \mathrm{~h}$. After incubation, the used medium was replaced with $180 \mu \mathrm{l}$ fresh medium and $20 \mu \mathrm{l}$ MTT solution $(10 \mathrm{mM})$ with subsequent incubation for $3 \mathrm{~h}$. After that, the medium was replenished with $150 \mu \mathrm{l}$ of DMSO (to dissolve formazan crystals) per well and incubated for $60 \mathrm{~min}$ in dark. The absorbance was measured using a microplate reader at $590 \mathrm{~nm}$.

\section{Haemo-compatibility analysis}

Isolation of human RBC's. Blood was drawn from healthy donors, heparinized, and centrifuged at $500 \times g$ for $30 \mathrm{~min}$ at room temperature. This gave an upper layer of plasma, a buffy coat consisting of mononuclear cells and a pellet of RBC's. The pellet was separated, washed thrice, and diluted 1 : 10 with PBS before subjecting to hemolysis assay. Briefly, to the pellet, RPMI 1640 medium containing 10\% autologous plasma, sodium bicarbonate $\left(2 \mathrm{mg} \mathrm{ml}^{-1}\right)$, penicillin $\left(100 \mathrm{IU} \mathrm{ml}^{-1}\right)$, streptomycin $\left(100 \mathrm{mg} \mathrm{ml}^{-1}\right)$, and gentamicin $\left(30 \mathrm{mg} \mathrm{ml}^{-1}\right)$, were added. The cells were maintained at $37{ }^{\circ} \mathrm{C}$ temperature, $5 \% \mathrm{CO}_{2}$ and $95 \%$ air in the humidified atmosphere in $\mathrm{a} \mathrm{CO}_{2}$ incubator. The RBCs were treated with quantum curcumin at $(10 \mu \mathrm{M}, 20 \mu \mathrm{M}, 30 \mu \mathrm{M}$, $40 \mu \mathrm{M}, 50 \mu \mathrm{M}, 60 \mu \mathrm{M}$, and $70 \mu \mathrm{M}$ ) concentrations and the toxicity was analyzed through the haemolytic studies. Briefly, to $100 \mu \mathrm{l}$ of the RBC suspension, $400 \mu \mathrm{l}$ of the desired concentration of quantum curcumin suspended in PBS was added. $400 \mu \mathrm{l}$ of $\mathrm{H}_{2} \mathrm{O}$ and $\mathrm{PBS}$ served as the positive and negative controls respectively. After incubation for $3 \mathrm{~h}$, the samples were vortexed, centrifuged and the supernatant was collected. The absorbance of the supernatant at $577 \mathrm{~nm}$ was recorded and the percentage hemolysis calculated by the formula:

(Sample absorbance - absorbance of negative control) $\div$ (absorbance of positive control - absorbance of negative control)

$$
\times 100
$$

\section{Membrane integrity analysis by lactate dehydrogenase (LDH) assay}

The cytotoxicity of quantum curcumin was assessed using Vero cells by measuring lactate dehydrogenase (LDH) activity (LDHCytotoxicity Assay Kit, BioVision, Inc., Milpitas, CA) in the culture media wherein the known cytotoxic $\mathrm{MoS}_{2}$ QDs were used as a reference for comparisons (in concentration range 10 $\mu \mathrm{M}, 20 \mu \mathrm{M}, 40 \mu \mathrm{M}, 80 \mu \mathrm{M}, 160 \mu \mathrm{M})$. Briefly, the $12 \mathrm{~h}$ treated cells were spun at $400 \times g$ for $5 \mathrm{~min}$ and the growth medium was collected. The broth and the $\mathrm{LDH}$ reagent was incubated in the ratio of $2: 1$ for $30 \mathrm{~min}$ followed by the absorbance reading at $500 \mathrm{~nm}$.

\section{Reactive oxygen species production analysis}

$2^{\prime}, 7^{\prime}$-Dichlorfluorescein-diacetate (DCFH-DA) based analysis for ROS production using flow cytometry. Endogenous reactive oxygen species (ROS) production was monitored by flow cytometry using $2^{\prime}, 7^{\prime}$-dichlorofluorescein-diacetate (DCFH-DA). The cells were treated with $70 \mu \mathrm{M}$ concentrations of quantum curcumin and $\mathrm{MoS}_{2}$ for $48 \mathrm{~h}$ and the cells were harvested upon centrifugation at $5000 \times g$ for $20 \mathrm{~min}$. The pelleted cells were washed thrice with phosphate-buffered saline (PBS, $\mathrm{pH} \sim 7.2$ ) and then cell density was adjusted to $10^{6}$ by suspending the cells in PBS. The resuspended cells were then incubated for $30 \mathrm{~min}$ with $5 \mu \mathrm{M}$ DCFH-DA. After treatment with quantum curcumin and staining, ROS production was analyzed on a BD Accuri C6 Flow cytometer. The acquisition was performed with BD Accuri C6 software based on light-scatter and fluorescence signals resulting from $20 \mathrm{~mW}$ laser illumination at $488 \mathrm{~nm}$. Light-scatter measurements and fluorescence measurements were acquired logarithmically. Signals corresponding to forward and side scatter (FSC and SSC) and fluorescence were accumulated; the fluorescence signal (pulse and measurements) was collected by FL-1 (DCFH-DA) band-pass filters. Threshold levels were set on SSC to eliminate noise or particles (i.e. cellular debris) much smaller than intact cells. Bacterial cells were gated according to FSC/SSC signals and samples were acquired at a low sample rate $\left(14 \mu \mathrm{lmin}^{-1}\right)$ to ensure that the event rate was lower than 2000 events $\mathrm{s}^{-1}$. A total of 100000 events was acquired for each sample.

Bacterial strains and culture conditions. The study was conducted on the 11 isolated $P$. gingivalis strains of the patients with chronic periodontitis. Besides, P. gingivalis (ATCC 33277), A. viscosus (ATCC 29522) and $S$. mutans (ATCC 25175) were also investigated for their response towards the drug. These isolates were grown in pre-reduced Brain heart infusion (BHI) broth containing $1 \mathrm{mg} \mathrm{ml}^{-1}$ yeast extract, $5 \mathrm{mg} \mathrm{ml}^{-1}$ hemin, and $1 \mathrm{mg}$ $\mathrm{ml}^{-1}$ menadione in an anaerobic system Anoxomat in an atmosphere of $80 \% \mathrm{~N}_{2}, 10 \% \mathrm{CO}_{2}$, and $10 \% \mathrm{H}_{2}$ at $35{ }^{\circ} \mathrm{C}$.

\section{Growth inhibition assays of quantum curcumin (CurQDs)}

Minimum inhibitory concentration determination. Minimum inhibitory concentrations of CurQDs were determined against $P$. gingivalis ATCC 33277, A. viscosus ATCC 29522 and $S$. mutans ATCC 25175 primarily. However, MIC was also determined against 11 clinical isolates of $P$. gingivalis by the micro-broth dilution as described earlier with modifications. ${ }^{39}$

For native curcumin, the stock solution was prepared by dissolving $5.434 \mathrm{mM}$ of CurQDs in $1 \mathrm{ml}$ of deionized water and was diluted in a series of two-fold dilutions ranging from 1.114 $\mu \mathrm{M}$ to $17.826 \mu \mathrm{M}$ in sterile $\mathrm{BHI}$ broth (HiMedia laboratories, India) in a microtiter plate. The aforementioned bacteria were grown anaerobically in $10 \mathrm{ml}$ BHI broth for $48 \mathrm{~h}$. Bacterial cultures $(500 \mu \mathrm{l})$ were then diluted to $1.5 \mathrm{ml}$ fresh BHI broth. Each well of 96-well tissue culture plate was then inoculated with $170 \mu \mathrm{l}$ of standardized cell suspension $\left(10^{5} \mathrm{CFU} \mathrm{ml}{ }^{-1}\right)$ and incubated at $37{ }^{\circ} \mathrm{C}$ for next $48 \mathrm{~h}$ along with the $30 \mu$ diluted drug such that effective concentration of the drug per well ranges from 0.1114 to $8.913 \mu \mathrm{M}$ in two fold dilutions. The MIC 
was defined as the lowest concentration of CurQDs at which sharp colour change (from light pink to orange/reddish-orange) was observed after addition of $50 \mu \mathrm{l}$ of iodonitrotetrazolium chloride $\left(1 \mathrm{mg} \mathrm{ml}^{-1}\right)$. Positive controls did not contain any drug moiety while the sterile broth was used as negative control. For comparison, we also used metronidazole dissolved in the nutrient liquid medium as per CLSI guidelines.

Bacterial growth rate analysis. Besides the micro broth dilution method, the growth rates of these isolates were further analyzed spectrophotometrically employing Synergy H1 Hybrid Multi-Mode Reader. The growth curve of the test bacteria, cultivated in the presence and absence of quantum curcumin with respect to untreated control was further used to validate its antibacterial potential.

Briefly, the standard bacterial test inoculum $\left(10^{6} \mathrm{CFU} \mathrm{ml}{ }^{-1}\right)$ was prepared from the late-exponential phase of bacterial growth and were added $(10 \mu \mathrm{l})$ to the wells of 96 well microtiter plate already containing 2 fold lower and 2 fold higher dose than the MIC dose of quantum curcumin in $190 \mu \mathrm{l}$ of BHI broth such that its OD at $\lambda_{\max } 600 \mathrm{~nm}$ was approximately 0.01 . The optical density of each well was then monitored at $\lambda_{\max } 600 \mathrm{~nm}$ by periodic measurements after every $15 \mathrm{~min}$ for $4.5 \mathrm{~h}$. To determine the maximum growth rate of each isolate both in presence and absence of CurQDs, the slope of the linear part of the growth curve $\left(R^{2}, \geq 0.98\right)$ was determined for at least 5 data points of the semi-logarithmic plot of absorbance $\left(\ln \left[\mathrm{OD}_{600}\right]\right) v s$. incubation time (in hours). For exact determination of absorbance of bacterial growth, absorbances of drugs were subtracted from those of the cumulative absorbance readings.

Measurement of gingipains $\mathbf{R}$ and $\mathbf{K}$ activities. Gingipains $\mathbf{R}$ and $\mathrm{K}$ (Arg- and Lys-specific proteinases) activities were performed by the method described earlier with modifications. ${ }^{40}$ $P$. gingivalis ATCC 33277 and clinical isolates $(n=11)$ were cultured in BHI broth anaerobically for 7 days with the drug at different concentrations ranging from $0.557-17.826 \mu \mathrm{M}$. The bacterial suspension was then spun at $3000 \mathrm{rpm}$ for $10 \mathrm{~min}$ and the supernatant was then collected. The $100 \mu \mathrm{l}$ of thus obtained supernatant was then mixed with $100 \mathrm{mM}$ synthetic substrates benzoyl-L-arginine-4-methylcoumaryl-7-amide (for arginine-specific proteinase activity) and $t$-butyl-oxycarbonyl- $\mathrm{L}^{-}$ valyl-L-leucyl-L-lysine-4-methylcoumaryl-7-amide (for lysinespecific proteinase activity) in $20 \mathrm{mM}$ Tris-HCl buffer $(\mathrm{pH}$ 7.6) which was supplemented with $10 \mathrm{mM}$ cysteine, $100 \mathrm{mM}$ $\mathrm{NaCl}$, and $5 \mathrm{mM} \mathrm{CaCl}_{2}$ in a total volume of $1 \mathrm{ml}$. The reaction mixture was incubated at $37^{\circ} \mathrm{C}$ for 15 minutes and then the reaction was terminated by adding $2 \mathrm{mM}$ Na-p-tosyl-L-lysine chloromethyl ketone hydrochloride. The reaction product 7amino-4-methyl coumarin was measured spectrophotometrically at excitation/emission wavelength settings of 380/460 nm with Synergy H1 Hybrid Multi-Mode Reader. The proteinase activities were finally normalized against the negative control by subtracting the background absorbances from all the samples.

In silico analysis of binding of curcumin with gingipains ( $R$ and K). Molecular docking of gingipain R (PDB ID: 1CVR) with curcumin (ZINC ID: 899824) was performed to analyze binding affinity and interaction between the molecules using AutoDock
(Morris et al. 2009) tool with default parameter. Water molecule and other co-factors were removed; and hydrogen atoms were added to prepare protein structure before docking. Ligand was also prepared and docked into the active/binding site of the target molecule.

Determination of antibiofilm activity using tissue culture plate assay (TCP). The antibiofilm assay was performed as described earlier with minor modifications. ${ }^{25}$ Briefly, $P$. gingivalis (ATCC 33277), A. viscosus (ATCC 29522), S. mutans (ATCC 25175 ) and all the clinical isolates of $P$. gingivalis were initially grown in BHI broth anaerobically at $37^{\circ} \mathrm{C}$ for $48 \mathrm{~h}$ which was then diluted 1 : 100 in pre-reduced BHI broth containing $1 \mathrm{mg}$ $\mathrm{ml}^{-1}$ yeast extract, $5 \mathrm{mg} \mathrm{ml}^{-1}$ hemin, and $1 \mathrm{mg} \mathrm{ml}^{-1}$ menadione and allowed to grow anaerobically in an atmosphere of $80 \% \mathrm{~N}_{2}$, $10 \% \mathrm{CO}_{2}$, and $10 \% \mathrm{H}_{2}$ at $37^{\circ} \mathrm{C}$. A volume of $90 \mu \mathrm{l}$ of each diluted bacterial suspension was then dispensed into flat-bottom lysine coated polystyrene 96-well tissue culture plate and $10 \mu \mathrm{l}$ of drug solution was added to attain final concentrations ranging from 0.557 to $17.826 \mu \mathrm{M}$. Wells without drugs were set up as positive controls. Plates were incubated at $37^{\circ} \mathrm{C}$ with shaking at $110 \mathrm{rpm}$ for $24 \mathrm{~h}$ in the case where biofilm inhibitory action of the drugs was investigated. After incubation, biofilm was quantitated by crystal violet (CV) assay (Merck, Germany) as described earlier. ${ }^{25}$

Mixed biofilm formation by $P$. gingivalis, $S$. mutans and $A$. viscosus. For multi-species biofilm model studies, we selected control strains of $P$. gingivalis, $S$. mutans and A. viscosus which are commonly associated with chronic periodontitis. $S$. mutans, $P$. gingivalis and A. viscosus were maintained on Colombia blood agar at $37{ }^{\circ} \mathrm{C}$ in $5 \% \mathrm{CO}_{2}$. The overnight culture of $S$. mutans was grown for $24 \mathrm{~h}$ in $\mathrm{BHI}$ broth in capnophilic condition while $A$. viscosus and $P$. gingivalis were grown for $24 \mathrm{~h}$ in $\mathrm{BHI}$ broth in the anaerobic condition and finally, all the isolates were incubated for $48 \mathrm{~h}$ anaerobically $\left(85 \% \mathrm{~N}_{2}, 10 \% \mathrm{CO}_{2}\right.$, and $\left.5 \% \mathrm{H}_{2}\right)$. All bacterial cultures were standardized to 0.5 McFarland match by washing, centrifuging, and suspending in PBS. Briefly, the standardized bacterial suspension was diluted $1: 100\left(10^{5}\right.$ cells per $\mathrm{ml})$ in BHI broth containing $1 \%(\mathrm{w} / \mathrm{v})$ sucrose to a 6 -well plate. The bacterial suspensions were then incubated statically at $37^{\circ} \mathrm{C}$ in $5 \% \mathrm{CO}_{2}$ for $72 \mathrm{~h}$, with intermittent replacement with fresh broth every $24 \mathrm{~h}$.

The effect of native and quantum curcumin on mixed biofilm was investigated in two different growth conditions. In the first condition, P. gingivalis, S. mutans, and A. viscosus were grown together for $48 \mathrm{~h}$. After the biofilm was established, it was initially treated with said drugs for $60 \mathrm{~min}$ followed by thorough washing with PBS ( $\mathrm{pH}$ 7.2) to remove the residual drug. Finally, the biofilm was quantitated by crystal violet (CV) assay. In the second set of experiment, S. mutans and A. viscosus were first grown anaerobically for $24 \mathrm{~h}$ followed by the addition of $P$. gingivalis which was grown further for next $24 \mathrm{~h}$. The treatment regime with the said drugs was for $60 \mathrm{~min}$. The residual drug was then removed by thorough washing with PBS and the biofilm was estimated by CV-assay as described earlier. $^{\mathbf{4 2}}$

Biofilm analysis by confocal laser scanning microscopy. The TCP assay findings for mixed biofilm, wherein $P$. gingivalis was introduced later on to the antecedently formed biofilm of 

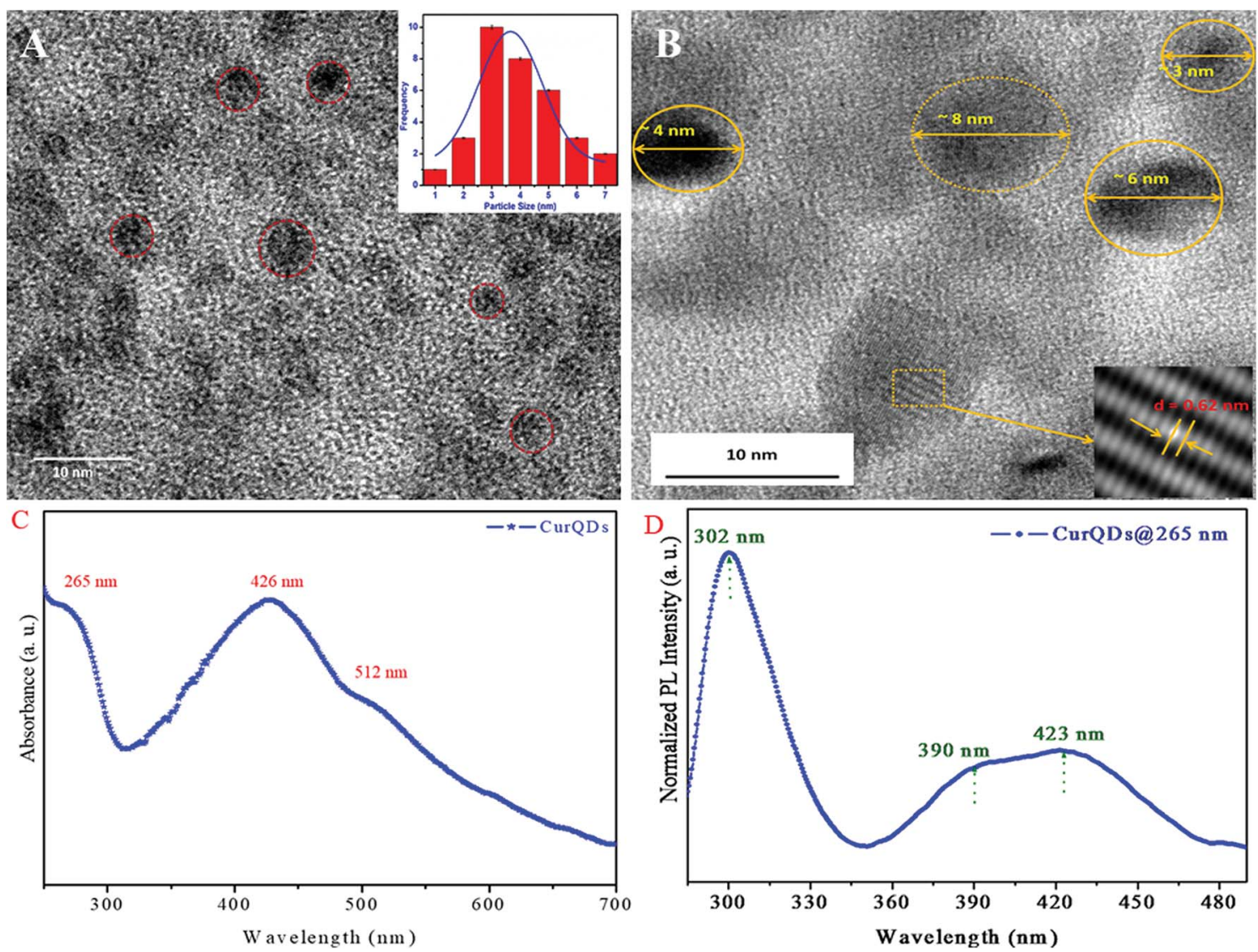

Fig. 1 TEM, HR-TEM, UV-visible absorption, and photo-luminescence (PL) spectra of quantum curcumin. (A) Transmission electron microscopy (TEM) images of CurQDs. Inset: the bar diagram of particle distribution fitted for a Gaussian function. (B) High-resolution transmission electron microscopy (HR-TEM) of CurQDs. Inset: shows an interlayer spacing of $\sim 0.63 \mathrm{~nm}$ corresponding to the (002) plane. (C) UV-visible absorption spectrum of CurQDs. (D) PL spectrum of CurQDs excited at wavelength $265 \mathrm{~nm}$.

S. mutans and A. viscous, were then validated by confocal laser scanning microscopy (CLSM). For confocal analysis, biofilm was grown in a chambered slide as described earlier. Briefly, fresh cultures of $S$. mutans and A. viscosus were first grown in capnophilic conditions for $36 \mathrm{~h}$ while $P$. gingivalis (ATCC 33277 ) was grown anaerobically in BHI broth for $36 \mathrm{~h}$. All the broth cultures were then diluted $1: 100$ with the fresh broth to OD at $\lambda_{\max } 600 \mathrm{~nm}$ equivalent to 0.2. Fifty microliters of a diluted suspension of representative bacterial isolates $(S$. mutans and A. viscosus) were then dispensed into chambered slide containing $450 \mu \mathrm{l}$ of BHI broth. The biofilm was grown anaerobically with shaking $110 \mathrm{rpm}$ for $36 \mathrm{~h}$. This was followed by addition of $50 \mu \mathrm{l}$ P. gingivalis (ATCC 33277) and was regrown anaerobically for the next $72 \mathrm{~h}$. These established biofilms were then exposed to 4 different concentrations of quantum curcumin (1.114-8.913 $\mu \mathrm{M})$ for $45 \mathrm{~min}$. Prior to staining, the residual broth was aspirated out followed by three washes with phosphate buffer ( $\mathrm{pH}$ 7.2). Biofilm was fixed using $4 \%(\mathrm{v} / \mathrm{v})$ paraformaldehyde for $60 \mathrm{~min}$ and washed thrice with PBS $(\mathrm{pH}$ 7.2). After fixation, concanavalin A, labelled with tetramethyl-rhodamine isothiocyanate (TRITC) (Life Technologies, USA) was used to visualize the biofilm matrix as it binds with the sugars of the biofilm. The stock $\left(1 \mathrm{mg} \mathrm{ml}^{-1}\right)$ of the conjugated lectin was prepared in $10 \mathrm{mM}$ phosphate buffer (pH 7.5). For use, stock solutions were diluted again with phosphate buffer to a lectin concentration of $10 \mu \mathrm{g} \mathrm{ml}^{-1}$. Tenmicroliters was the aliquot were added to the wells and incubated at room temperature for $20 \mathrm{~min}$ in the dark. After incubation, the residual dye was removed by washing with PBS thrice. The sections were then analyzed and images acquired using the Zeiss LSM 510 inverted confocal laser scanning microscope (Carl Zeiss, Jena, Germany). Optical sections of fluorescent specimens were obtained via a Plan-Neofluar $40 \times 1$ 1.3 oil objective with a z-step of $2.0 \mu \mathrm{m}$ using a HeNe laser $(\lambda=$ $543 \mathrm{~nm})$ and an argon laser $(\lambda=458 \mathrm{~nm})$ using a pinhole of 250. Each image was acquired within $2 \mathrm{~min}$, to minimize photo-degradation.

Statistical analysis. All the experiments were performed in triplicates and the data were based on the average of 3 different experiments. The data were expressed as mean values with the corresponding standard deviations (SD). Statistical significance between treated and control groups was analyzed by Mann-Whitney $U$ test and student's $t$-test (two-tailed, unequal variance) using GraphPad Prism version 5.1 (GraphPad Software, Inc., La Jolla, CA, USA). $P$-value of $<0.05$ was considered statistically significant. 


\section{Results}

TEM, HR-TEM, UV-visible absorption and photoluminescence (PL) spectra of CurQDs

The TEM micrograph of CurQDs is depicted in Fig. 1A CurQDs are encircled with red color. Inset of the Fig. 1A shows the particle distribution estimated over 30-35 particles. The particle distribution bar graph has been fitted for Gaussian function and the average particle size is found to be $3.5 \mathrm{~nm}$. The HR-TEM has been shown in the Fig. 1B. Inset therein shows an interlayer spacing of $\sim 0.63 \mathrm{~nm}$ corresponding to the (002) plane of curcumin.

UV-visible absorption spectra of CurQDs were recorded in water as depicted in Fig. 1C. One milliliter CurQDs suspension was used for photoluminescence studies using excitation wavelength $265 \mathrm{~nm}$ as represented in Fig. 1D. Three discrete absorption bands were obtained for CurQDs: one in UV region $(263 \mathrm{~nm})$ and two in the visible region (425 and $512 \mathrm{~nm})$.

\section{X-ray photoelectron spectroscopy (XPS) analysis}

XPS was used to study the chemical states and electronic structure of quantum curcumin (Fig. 2A and B). HR-XPS spectrum of C1s (Fig. 2A) was found deconvoluted into four peaks of binding energies $\sim 284.0 \mathrm{eV}, 285.5 \mathrm{eV}, 286.8 \mathrm{eV}$, and $288.8 \mathrm{eV}$ respectively. These four deconvoluted XPS peaks correspond to $\mathrm{sp}^{2}(\mathrm{C}=\mathrm{C}), \mathrm{sp}^{3}(\mathrm{C}-\mathrm{C} \& \mathrm{C}-\mathrm{H}), \mathrm{C}-\mathrm{OH}$ and $\mathrm{C}=\mathrm{O}$ binding energies respectively. Presence of $\mathrm{C}-\mathrm{OH}$ and $\mathrm{C}=\mathrm{O}$ at binding energies $\sim 286.6 \mathrm{eV}$ and $288.8 \mathrm{eV}$ confirm the presence of alcoholic and carbonyl (keto) functional groups of the CurQDs. HR-XPS spectrum of O1s is shown in the Fig. 2B where four deconvolutions appeared at positions $\sim 532 \mathrm{eV}, 532.4 \mathrm{eV}, 533.6 \mathrm{eV}$, and $534.3 \mathrm{eV}$ respectively. These peaks correspond to oxygen atoms, $\mathrm{O}=\mathrm{C}$ and $\mathrm{O}-\mathrm{C} \& \mathrm{O}-\mathrm{H}$ respectively which again confirm the no change in the chemistry of curcumin while being converted into quantum form.

\section{Raman spectroscopy}

Raman spectrum of quantum curcumin is presented in Fig. 3A. The spectrum was similar to that of the native curcumin indicating no chemical and structural change during synthesis. The absence of other additional peaks indicated the purity of the synthesis. In $1600-1800 \mathrm{~cm}^{-1}$ region, the peak at $1630 \mathrm{~cm}^{-1}$ is assigned to the vibration of $\vartheta(\mathrm{C}=\mathrm{O})$. The distal benzene rings of the curcumin molecule remain intact as expected after quantum dot formation as indicated by $\mathrm{C}-\mathrm{C}$ stretching of the aromatic ring at $1603 \mathrm{~cm}^{-1}$. At $1428 \mathrm{~cm}^{-1}$ stretching of phenolic $\mathrm{C}-\mathrm{O}$ is also observed. These are the signature peaks of curcumin which remained unaltered. At $\sim 1753 \mathrm{~cm}^{-1}$, a new broad-band appears in CurQDs possibly owing to keto-enol tautomerism (due to $\vartheta(\mathrm{C}=\mathrm{O})$ ). However, peaks at $1254 \mathrm{~cm}^{-1}$ and $1182 \mathrm{~cm}^{-1}$ were due to the stretchings of enolic $\mathrm{C}-\mathrm{OH}$ and $\mathrm{C}-\mathrm{O}-\mathrm{C}$ stretchings. Interestingly, a peak at $967 \mathrm{~cm}^{-1}$ is also noted that has appeared due to the in-plane bending of $\mathrm{C}-\mathrm{H}$.

\section{X-ray diffraction analysis}

The core size of CurQDs was estimated by Scherrer formula:

$$
D=0.9 \lambda / \beta \cos \theta
$$

where $\beta$ is the full width at half maximum of the peak, $\theta$ is the angle of diffraction, and $\lambda$ is the wavelength of the X-ray radiation. The diffraction pattern peaks at 17.2107, 21.118, 23.248, 24.675 , and $25.648(2 \theta)$ represent characteristics of the crystalline structure of quantum curcumin (Fig. 3B).

\section{Zeta potential}

The zeta potential of CurQDs was found to be $-24.25 \mathrm{mV}$ (Fig. 3C).

\section{Nuclear magnetic resonance spectroscopy}

${ }^{1}$ H NMR (500 MHz, DMSO-d 6 ). $\delta 3.82(\mathrm{~s}, 6 \mathrm{H}), 6.04(\mathrm{~s}, 1 \mathrm{H})$, $6.72(\mathrm{~s}, 1 \mathrm{H}), 6.75(\mathrm{~s}, 1 \mathrm{H}), 6.81(\mathrm{~d}, J=7.5 \mathrm{~Hz}, 2 \mathrm{H}), 7.14(\mathrm{~d}, J=$ $7.5 \mathrm{~Hz}, 2 \mathrm{H}), 7.31(\mathrm{~s}, 2 \mathrm{H}), 7.54(\mathrm{~d}, J=15.0 \mathrm{~Hz}, 3 \mathrm{H}), 9.65(\mathrm{~s}, 2 \mathrm{H})$ (Fig. 4A).

${ }^{13}$ C NMR (125 MHz, DMSO-d $\left.{ }_{6}\right) . \delta 55.6,100.8,111.3,115.6$, 121.0, 123.1, 126.3, 140.7, 147.9, 149.3, 183.2 ppm (Fig. 4B).

\section{Biocompatibility assays}

Haemo-compatibility analysis. The membrane stability of the erythrocytes indicates the effect of various in vitro damage levied on it by the quantum dots under investigation. Therefore, in vitro haemo-compatibility assay becomes relevant and
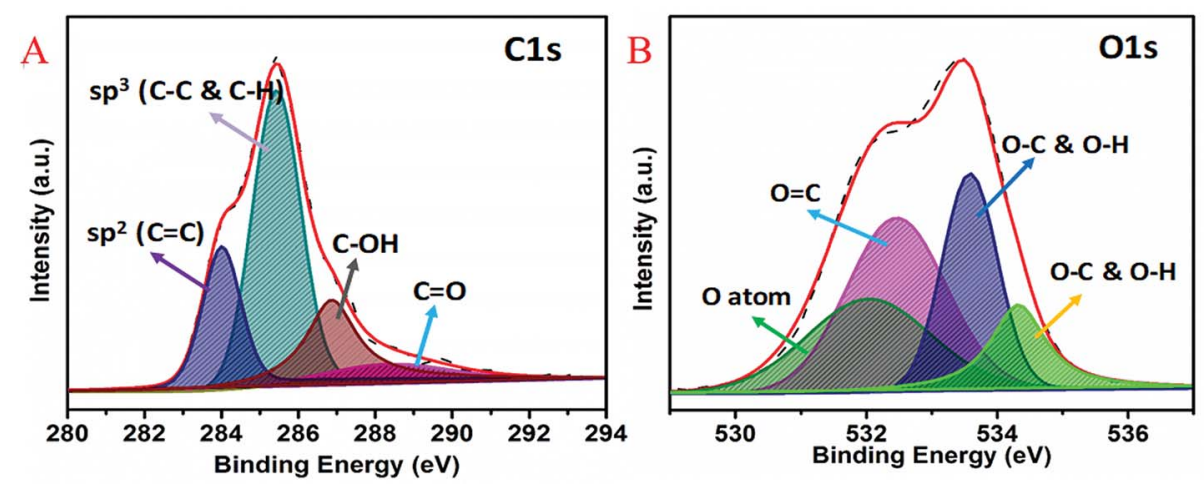

Fig. 2 High-resolution (A) C1s and (B) O1s XPS survey of quantum curcumin. 

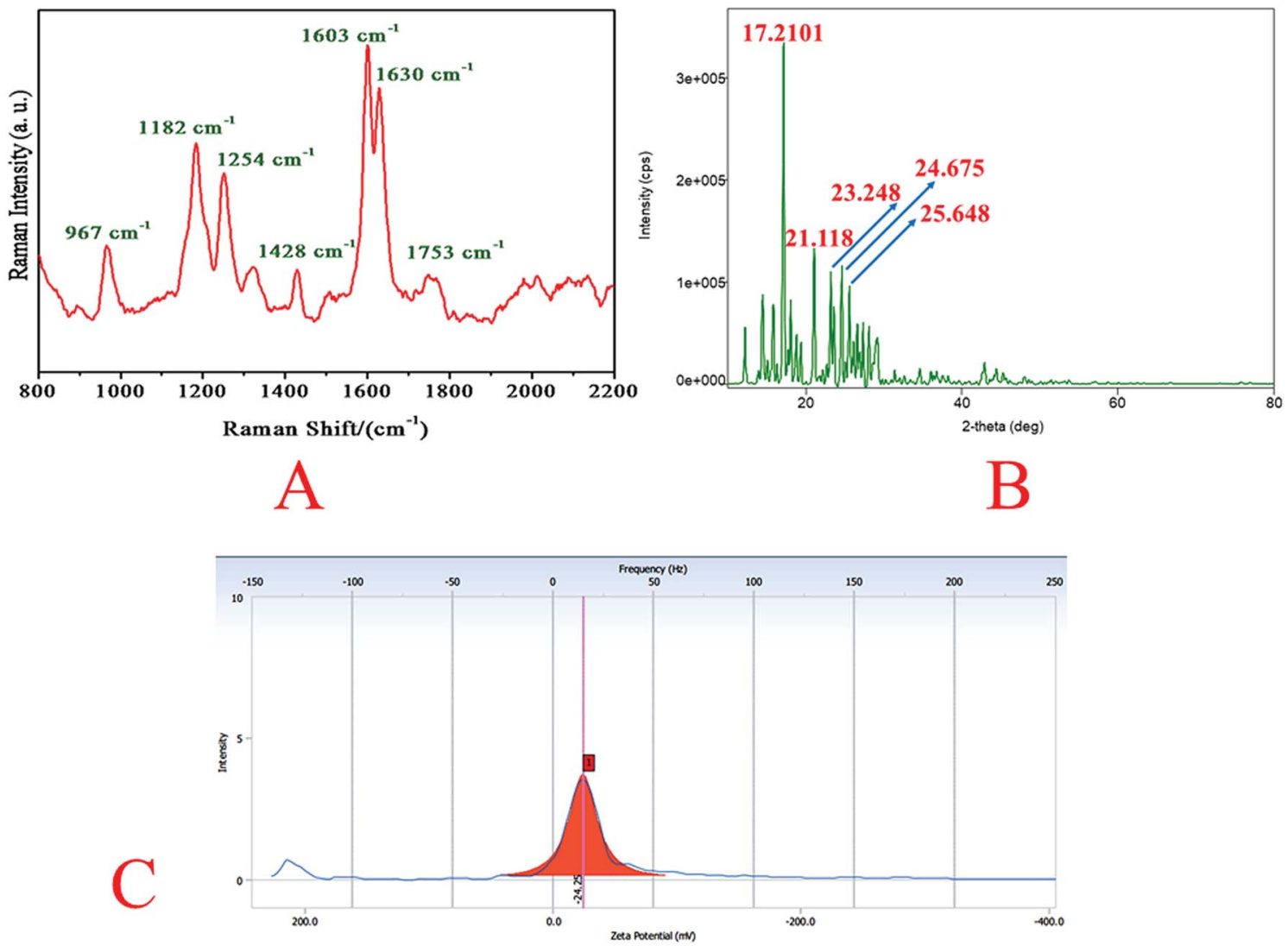

Fig. 3 Raman spectrum, X-ray diffraction (XRD) pattern, and zeta potential of quantum curcumin. (A) Raman spectrum of quantum curcumin revealing signature peaks at $1630 \mathrm{~cm}^{-1}$ and $1603 \mathrm{~cm}^{-1}$ corresponding to vibration $(\vartheta)$ of $(C=O)$ and $C-C$ stretching of the aromatic ring of curcumin. Besides, peak at $\sim 1753 \mathrm{~cm}^{-1}$ indicates $\vartheta(C=0)$ possibly due to keto-enol tautomerism. (B) X-ray diffractogram of quantum curcumin depicts signature peaks at $2 \theta \sim 17.2107,23.248$ and 24.675. (C) Zeta potential of quantum curcumin.

reliable in ensuring the compatibility of drug particle for systemic use. As can be seen in Fig. 5A, the hemolysis was found to be $0.11 \pm 0.023,1.26 \pm 0.440,2.23 \pm 0.289,3.789 \pm 0.316$, and $6.34 \pm 0.441 \%$ (corresponding percent viability $99.89 \pm$ $0.0833,98.74 \pm 0.440,97.77 \pm 0.289,96.22 \pm 0.316,93.66 \pm$ $0.441 \%$ ) in the presence of quantum curcumin at the much higher concentrations compared to MIC $(10 \mu \mathrm{M}, 20 \mu \mathrm{M}, 40 \mu \mathrm{M}$, $80 \mu \mathrm{M}$, and $160 \mu \mathrm{M}$ respectively). Of note, no significant haemolysis was observed up to $100 \mu \mathrm{M}$ concentration. These results suggest that the synthesized quantum curcumin are non-toxic to human erythrocytes.

\section{Cell leakage study}

LDH assay. Cell viability assays was further investigated using LDH assay to assess the toxicity of quantum curcumin to eukaryotic cells. The structural damage to the cell, which may be instigated either by apoptosis or necrosis or by any other agent that may adversely alter the cell membrane or the mitochondria, prompts the release of lactate dehydrogenase (a cytosolic enzyme) from leaky membranes into the culture medium. Therefore, we used lactate dehydrogenase (LDH), as the marker for membrane integrity to indirectly assess cytotoxicity. Table 1 shows the LDH activity status (in terms of mean absorbance) in percentage after $12 \mathrm{~h}$ exposure of the cells to the CurQDs and $\mathrm{MoS}_{2}$ QDs. At any given time, Vero cells incubated with CurQDs at various concentrations $(10 \mu \mathrm{M}, 20 \mu \mathrm{M}, 40 \mu \mathrm{M}, 80 \mu \mathrm{M}$, and 160 $\mu \mathrm{M})$ showed observably lower LDH activity than the group inoculated with $\mathrm{MoS}_{2}$ QDs in the same concentration range, demonstrating that $\mathrm{MoS}_{2}$ QDs fostered cell leakage in a dosedependent manner (Fig. 5B). This indicates a very good biocompatibility. In short, CurQDs does not foster cell leakage even at the higher concentration which was in consonance with the phase contrast micrographs.

The formula used for $\%$ cytotoxicity calculation is as follows:

(Mean absorbance of treated cells - absorbance of medium - absorbance of cell and medium

(absorbance of Triton $\mathrm{X}$ treated cell - absorbanc of cell and medium) 

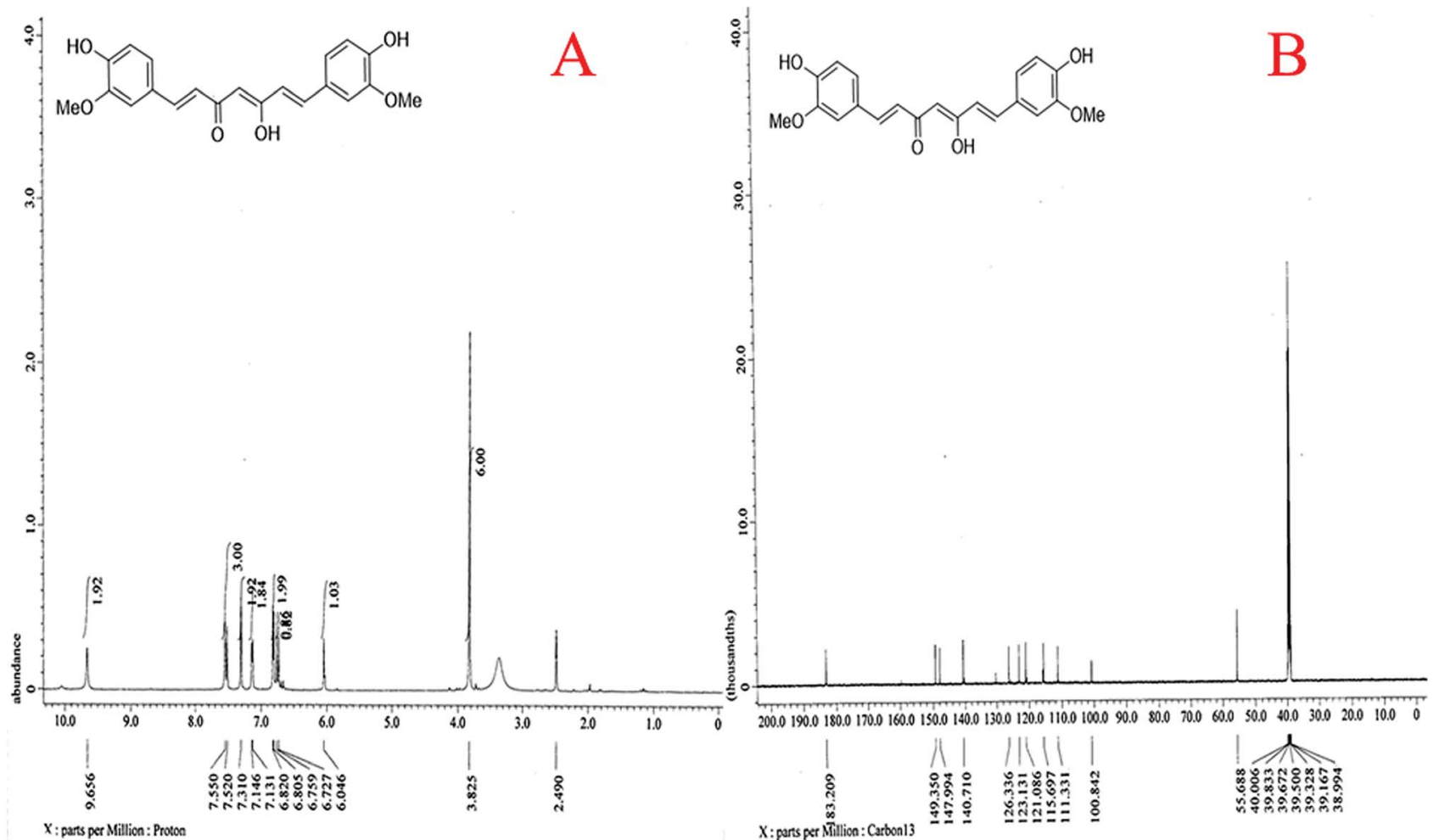

Fig. 4 Nuclear magnetic resonance (NMR) spectra of quantum curcumin. (A) ${ }^{1} \mathrm{H}$ NMR $\left(500 \mathrm{MHz}, \mathrm{DMSO}-\mathrm{d}_{6}\right): \delta 3.82(\mathrm{~s}, 6 \mathrm{H}), 6.04(\mathrm{~s}, 1 \mathrm{H}), 6.72(\mathrm{~s}$, $1 \mathrm{H}), 6.75(\mathrm{~s}, 1 \mathrm{H}), 6.81(\mathrm{~d}, J=7.5 \mathrm{~Hz}, 2 \mathrm{H}), 7.14(\mathrm{~d}, J=7.5 \mathrm{~Hz}, 2 \mathrm{H}), 7.31(\mathrm{~s}, 2 \mathrm{H}), 7.54(\mathrm{~d}, J=15.0 \mathrm{~Hz}, 3 \mathrm{H}), 9.65(\mathrm{~s}, 2 \mathrm{H}) .(\mathrm{B}){ }^{13} \mathrm{C} \mathrm{NMR}\left(125 \mathrm{MHz}, \mathrm{DMSO}-\mathrm{d}_{6}\right)$ : $\delta 55.6,100.8,111.3,115.6,121.0,123.1,126.3,140.7,147.9,149.3,183.2 \mathrm{ppm}$.

MTT assay. The in vitro cellular viability in presence of quantum curcumin was evaluated by MTT assay (Fig. 5C). We comparatively quantitated the amount of purple formazan formed in treated Vero cells and the control. This killing potential of the drug can be reckoned effectively by this method. Incubation of Vero cells with CurQDs did not influence cell viability in the tested range $(10-160 \mu \mathrm{M})$ which can be inferred from the fact that upon exposure to $10 \mu \mathrm{M}$ CurQDs, cell viability was around 99\% which remained 96.7\% (almost unchanged) when exposed to $160 \mu \mathrm{M}$. Unlike quantum curcumin, the $\mathrm{MoS}_{2}$ QDs adversely affected the cell viability in a concentrationdependent manner. For instance, at $10 \mu \mathrm{M}$ concentration, around $96 \%$ cell viability was noted but as the concentration was raised to $160 \mu \mathrm{M}$; cell viability was reduced to $<20 \%$. Although, with escalated concentration, viability was reduced more but no significant linear relationship was documented.

\section{Flow cytometry}

The Vero cells were exposed to $160 \mu \mathrm{M}$ concentrations of quantum curcumin and $\mathrm{MoS}_{2}$ QDs, followed by evaluation of ROS generation by probing with $2^{\prime}, 7^{\prime}$-dichlorfluoresceindiacetate (DCFH-DA) using flow cytometry. We observed significant differences in the ROS generation profile of the two discrete QDs as evident from the increased intensity/count in the DCF fluorescence (Fig. 6) and increase in the cell count (those took up the dye) when exposed to $\mathrm{MoS}_{2}$ quantum dots. $\mathrm{MoS}_{2}$ QD treated cells exhibited a significant increase in the
DCF fluorescence compared to the control, whereas no significant increase in the fluorescence was perceived when the cells were treated with quantum curcumin. This showed that CurQDs yielded significantly low ROS in comparison to the $\mathrm{MoS}_{2}$ QDs. Interestingly; the administration of quantum curcumin has improved the cellular health as evidenced with the restoration and increase of cell population in the gated region (more granularity) under investigation. The results of flow cytometry are in agreement with the results obtained from preceding assays.

\section{Antimicrobial assay of quantum curcumin against clinical isolates of Porphyromonas gingivalis and select reference strains}

We tried to observe antibacterial activity of CurQDs over eleven clinical isolates of $P$. gingivalis isolated from the patients of chronic periodontitis as well as antibiofilm activity of the drug over the individual as well as mixed biofilm of $P$. gingivalis (ATCC 33277), A. viscosus (ATCC 29522), and S. mutans (ATCC 25175).

Determination of minimum inhibitory concentration. Quantum curcumin drastically deterred the growth of the bacteria under investigation. Whereas the MIC of native curcumin against tested periodontopathic bacteria was observed to be beyond the tested range. The MIC and MBC of CurQDs for $P$. gingivalis (ATCC 33277), A. viscosus (ATCC 29522), and S. mutans (ATCC 25175) was found to be $1.114 \mu \mathrm{M}, 1.114 \mu \mathrm{M}$ and $2.228 \mu \mathrm{M}$ 


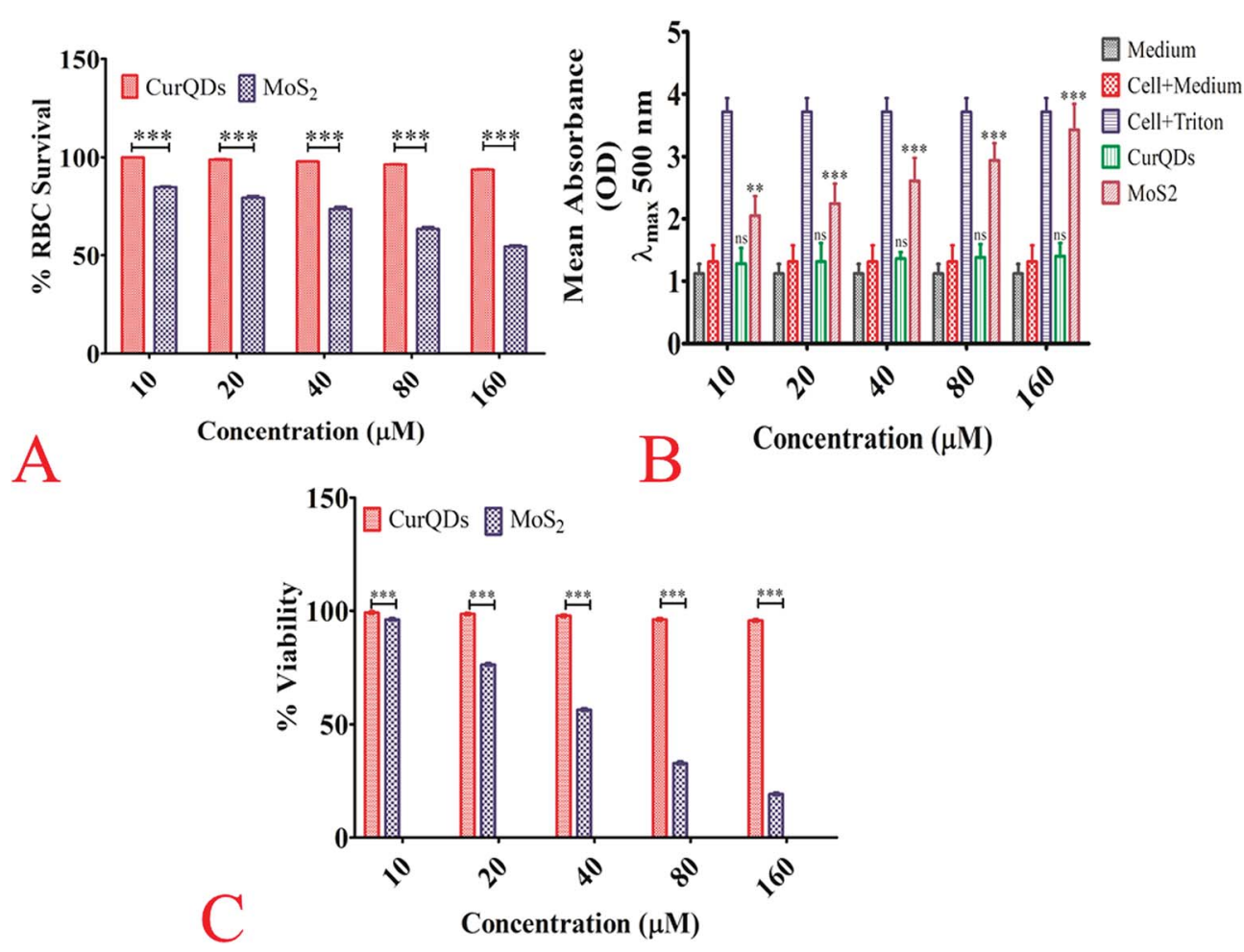

Fig. 5 Biocompatibility evaluation. (A) Haemo-compatibility evaluation of quantum curcumin vis-à-vis MoS 2 QDS. The plot corresponds the percent viability of $99.89 \pm 0.0833,98.74 \pm 0.440,97.77 \pm 0.289,96.22 \pm 0.316,93.66 \pm 0.441$ in the presence of quantum curcumin at concentrations $10 \mu \mathrm{m}, 20 \mu \mathrm{m}, 40 \mu \mathrm{m}, 80 \mu \mathrm{m}$, and $160 \mu \mathrm{m}$ respectively showing almost no/minimal toxic effects over rbcs. While its counterpart $\mathrm{MoS}_{2}$ QDS had shown significant haemolysis at all concentrations. (B) Lactate dehydrogenase assay for cytotoxicity evaluation. The plot shows relative enzyme activity in terms of absorbance. The experiment had three controls, the first one being medium alone; the second one was medium along with the cells while the third control was the cells treated with $2 \%$ Triton X 100 . As evident from the plot, the LDH activity was insignificant in the group treated with quantum curcumin indicating negligible cell lysis while the MoS $_{2}$ QDS treated group had shown dose dependent cell lysis with maximum LDH activity at the concentration of $160 \mu \mathrm{m}$. (C) Cell viability analysis using methylthiazoltetrazolium bromide (MTT) assay. The result of MTT assay is in consonance with the results above cited. The cellular viability of Vero cells remained intact even at highest treated concentration of CurQDs while its counterpart $\mathrm{MoS}_{2}$ had shown pronounced killing $(<20 \%)$ at $160 \mu \mathrm{m}$ concentration.

respectively (Table 2). However, in the case of clinical isolates of $P$. gingivalis, a range of MIC was obtained ranging from $0.557-$ $8.913 \mu \mathrm{M}$. Out of 11 isolates; the MIC against 2 isolates were found to be $8.913 \mu \mathrm{M}$, rest all were completely inhibited at or below $2.228 \mu \mathrm{M}$. On the contrary, its native counterpart failed to exhibit any effect against clinical isolates even at a concentration of $17.826 \mu \mathrm{M}$ (Fig. 7).

Growth rate analysis. Growth curves of the $P$. gingivalis (ATCC 33277), A. viscosus (ATCC 29522) and S. mutans (ATCC 25175) strains with and without drugs were investigated (Fig. 8A-C). Their growth was inhibited by CurQDs at a minimal concentration of $0.557 \mu \mathrm{M}$ and at concentrations $>8.913 \mu \mathrm{M}$, complete inhibition of the bacterial growth was manifested. Native curcumin was not effective in the tested range. These results depict the strong antibacterial activity of CurQDs against $P$. gingivalis even at significantly low concentrations.

Inhibitory effect of quantum curcumin on $P$. gingivalis gingipains (Arg- and Lys-specific proteinases). As shown in Fig. 9, CurQDs inhibited both Arg- and Lys-specific proteinases activities of clinical isolates as well as $P$. gingivalis (ATCC 33277) in a dose-dependent manner $(P<0.001)$. CurQDs dampened the Arg- and Lys-specific proteinase by $58.2 \%$ and $51.4 \%$ respectively at $0.557 \mu \mathrm{M}$ while at the $17.826 \mu \mathrm{M}$ concentration $98.7 \%$ and $89.4 \%$ inhibition was noted. The results observed here are in consonance with those obtained from TCP assay. However, the inhibition of Lys-specific proteinases by CurQDs was less pronounced compared to Arg-specific proteinases.

In silico validation of quantum curcumin mediated inhibition of gingipains. The molecular docking studies have been carried out to evaluate the binding affinity and binding energy of curcumin with gingipains $\mathrm{R}$ and $\mathrm{K}$. The important binding interactions of the actively docked conformations of curcumin with the target proteins were identified. A total of 10 binding modes of curcumin with gingipain $\mathrm{R}$ were predicted. Lowest binding energy shows highest binding affinity between receptor and ligand, therefore, highest binding affinity mode of curcumin was used to analyze its interaction with gingipain $\mathrm{R}$ protein. The interaction of amino acids SER-156, GLY-210, HIS211, GLY-212, VAL-242, ALA-243, CYS-244, GLN-282, TYR-283, TRP-284, ALA-285, PRO-286, TYR-325, and ASP-328 were observed around 4 A of ligand (Fig. 10A).

Similarly, molecular docking were also performed between gingipain $\mathrm{K}$ (PDB ID: 4RBM) with curcumin to analyze their interaction. The interaction of THR-442, ALA-443, HIS-444, GLY445, ASN-475, CYS-476, CYS-477, ILE-478, ASN-510, SER-511, 
站

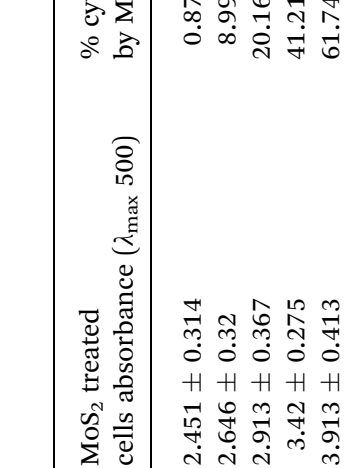

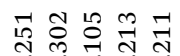

तิ่

$\mathrm{H}+\mathrm{H}+\mathrm{H}+\mathrm{H}$

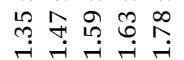

욱유용

\section{Analy
assay}

Individual isolates \& mixed. The biofilm inhibition by quantum curcumin was concentration dependent and was observed to be variable among different oral pathogens. At the concentration $0.557 \mu \mathrm{M}$, quantum curcumin was found to inhibit the biofilm formation by $61 \%$ and $53 \%$ in Porphyromonas gingivalis and Actinomycetemcomitans viscosus respectively. Interestingly, CurQDs were found to be poorly effective against Streptococcus mutans biofilms at the said concentration where merely $35 \%$ inhibition was perceived. But, no sooner, the concentration was escalated to $17.826 \mu \mathrm{M}$ then, significant inhibitions of $97 \%, 91 \%$, and $89 \%$ were observed in individual biofilms of $P$. gingivalis, A. viscosus, and $S$. mutans respectively (Table 3) (Fig. 11). However, the trend of inhibition was found to be different when quantum curcumin was tested against mixed biofilm of $P$. gingivalis, A. viscosus, and S. mutans. The two distinctly grown mixed biofilms responded differently. In the case of mixed biofilm of the three isolates grown simultaneously, at $0.557 \mu \mathrm{M}$ concentration, only $49 \%$ of biomass reduction was observed. In this condition also, the inhibition was found to be concentration dependent with maximum inhibition (87.28\%) observed at $17.826 \mu \mathrm{M}$ concentration. This is lesser than the inhibition of any individual biofilm of the said bacteria. However, in the case of second type of biofilm wherein $P$. gingivalis was introduced later on in the antecedently formed biofilm of $S$. mutans and A. viscosus ( $24 \mathrm{~h}$ old), the quantum curcumin was found to be comparatively less effective in inhibition, although the inhibition was concentration dependent. Unlike individually formed biofilms and the previously described mixed biofilm, at $0.557 \mu \mathrm{M}$ and $17.826 \mu \mathrm{M}$ concentrations, only $28 \%$ and $\sim 82 \%$ of inhibition were manifested.

\section{Confocal microscopic evaluation of the effect of CurQDs on biofilm architecture}

P. gingivalis, S. mutans, and A. viscosus isolates were selected and grown simultaneously for the biofilm study because of denser and relatively robust biofilm forming potential together, which is more closely associated with chronic periodontitis. The degradative effect of quantum curcumin on mixed biofilm was examined using CLSM. As shown in Fig. 12A and B, CurQDs corroded the mixed biofilm in a dose-dependent manner $(P<$ 0.001). With initial exposure to $0.557 \mu \mathrm{M}$ CurQDs, the biofilm matrix slackened off (became more porous which indicates the loosening of the matrix material) which can be seen unambiguously in Fig. 12A(B). This loosening intensified to its maxima when the exposed concentration was escalated to $8.913 \mu \mathrm{M}$ (Fig. 12A(D)). Interestingly, upon exposure of $17.826 \mu \mathrm{M}$, one can note the scattered planktonic cells. These results are in consonance with the observations of TCP assay. 

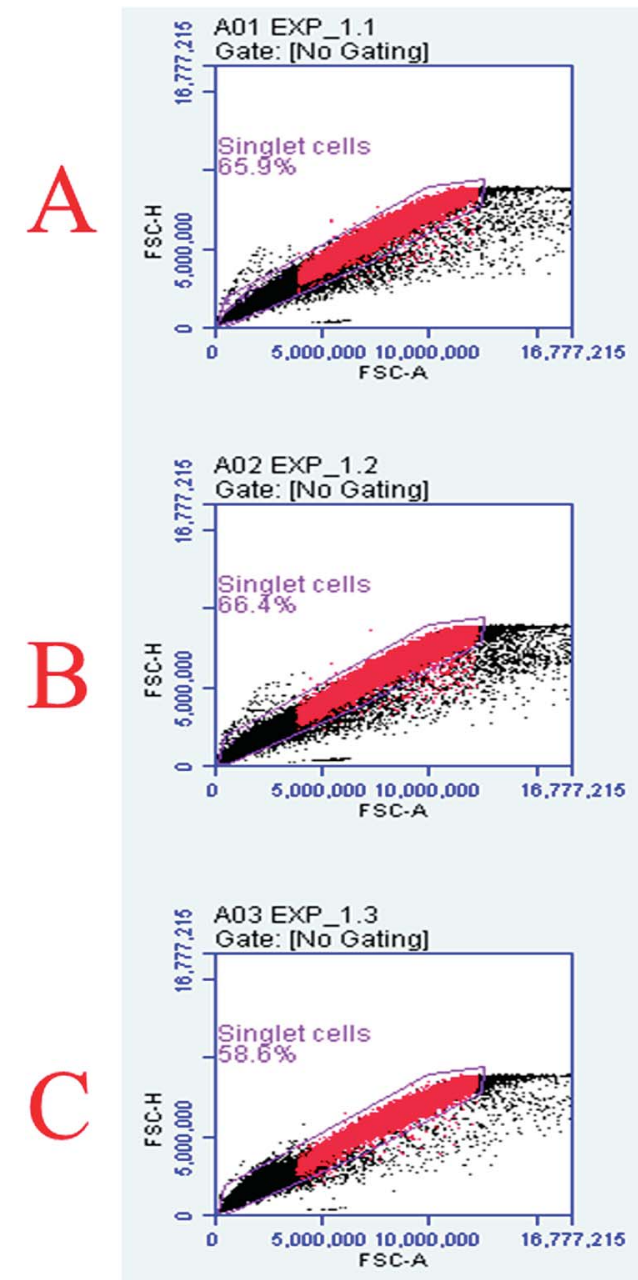
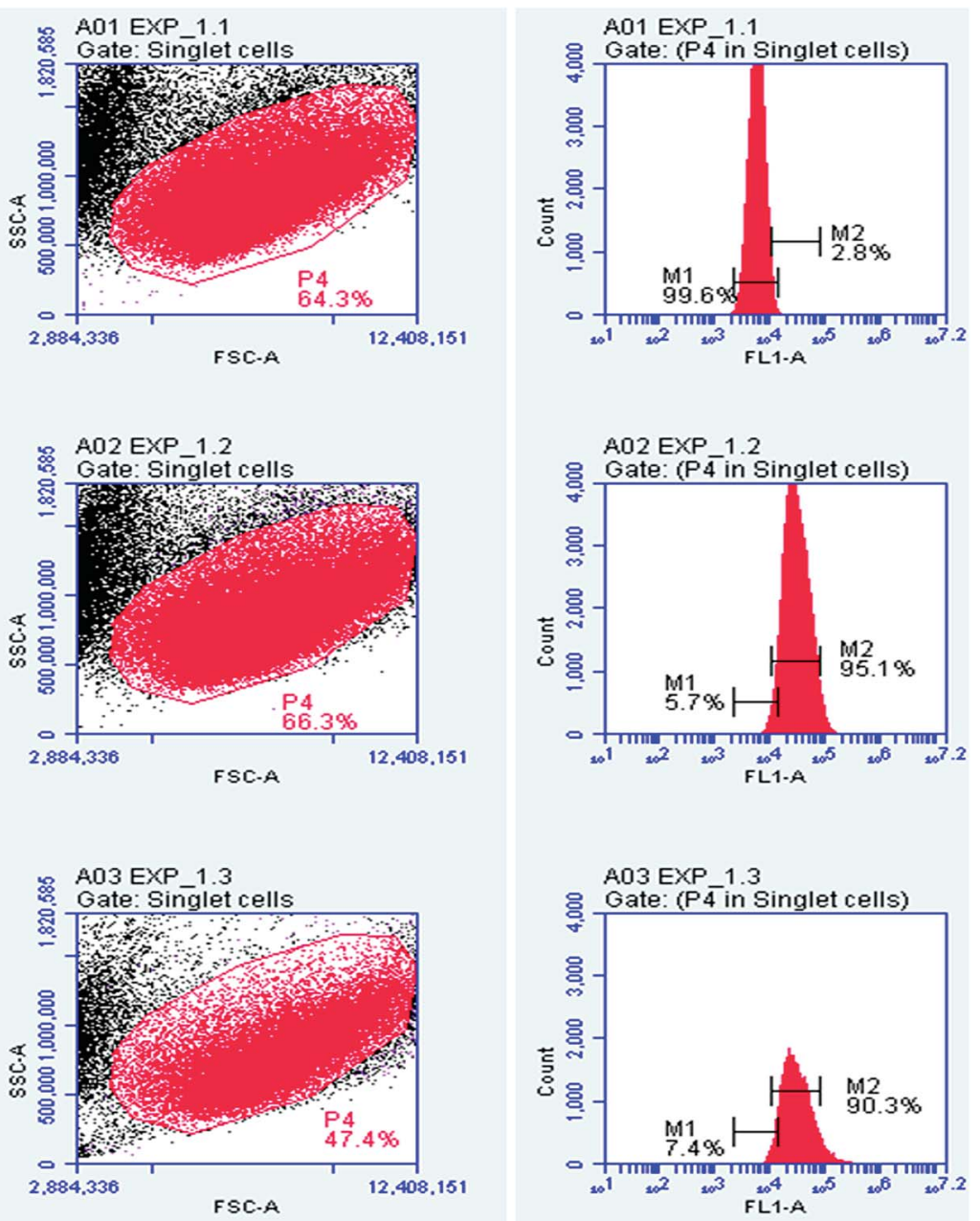

Fig. 6 Flow cytometry analyses of the cell cultures stained with DCFH-DA to probe ros generation in the groups treated with two discrete quantum dots. The symbols, pattern and colours used here remained the same for every panel. (A) Total 100000 cells were acquired for each flow cytometry analysis. Histograms of untreated logarithmic vero cells labeled with DCFH-DA. The first panel shown herein at proximal left depicts the bivariate dot plot diagram of the intensity (height) of forward scatter versus area of forward scatter to select the singlet cells. The singlet cells were gated and its population was found to be $65.9 \%$. Moving right to this panel (the middle one) is a plot diagram of the side-scatter versus forward scatter depicting the cellular granularity or internal complexity. At the distal most panel of $A$, intensity of untreated cell population was captured for further comparisons in FL1A channel. (B) Histograms of MoS 2 QDS treated logarithmic Vero cells labeled with DCFH-DA. The panels show the increase in cell population (66.3\%) that had taken up DCFH-DA indicating increased ros generation. Similarly, the distal most panel shows that the majority of cell population had shifted right with highly significant intensity, which embarks the pronounced ROS generation and damage. (C) Histograms of CurQDs treated logarithmic vero cells labeled with DCFH-DA. The panels show the decrease in cell population $(47.4 \%)$ that had taken up DCFH-DA indicating increased ros generation. The distal most panel shows that the majority of cell population had shifted right but the intensity was significantly low, which depicts the ROS quenching by the quantum curcumin.

For the assessment of the nature of the interaction of the quantum curcumin and the matrix, we selectively studied (Fig. 12B) the panel D of Fig. 12A. One can note the ubiquitous distribution of quantum curcumin (as green fluorescent signals, Fig. 12B(B)) in the biofilm matrix (red fluorescent signals, Fig. $12 \mathrm{~B}(\mathrm{~A})$. Panel $12 \mathrm{~B}(\mathrm{C})$ shows the intermediary

Table 2 Minimum inhibitory concentration of quantum curcumin

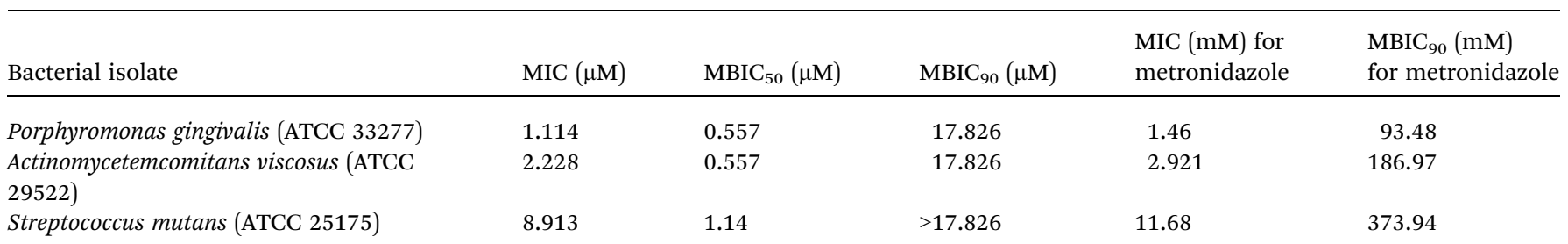




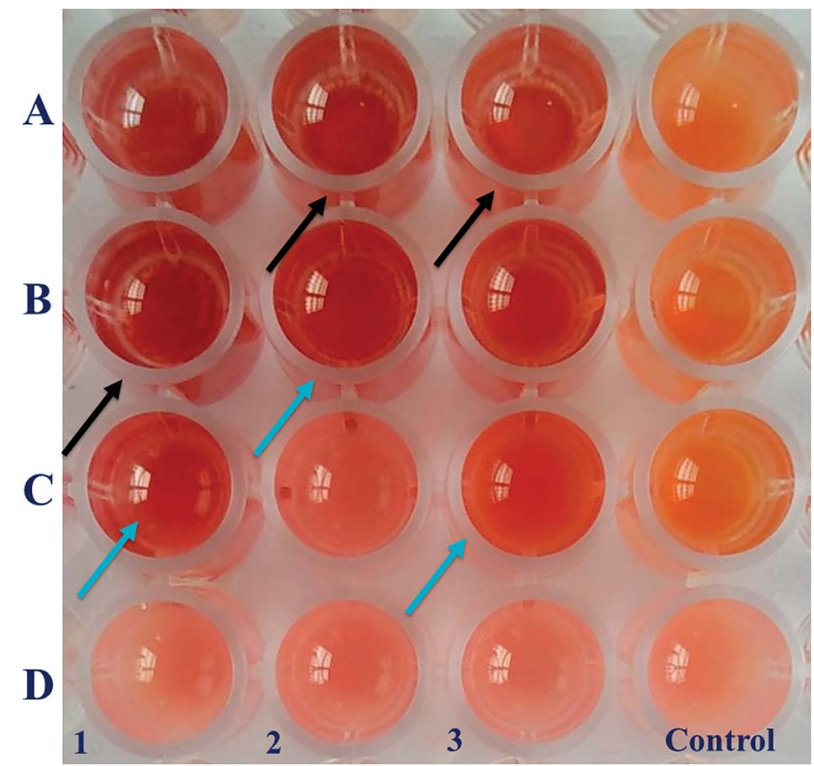

Fig. 7 MIC determination of CurQDs against $P$. gingivalis (ATCC 33277), S. mutans (ATCC 25175), and A. viscosus (ATCC 29522). Lanes 1,2 and 3 are respectively of $P$. gingivalis (ATCC 33277), S. mutans (ATCC 25175), and A. viscosus (ATCC 29522). The MIC was found to be $1.114,2.228$, and $1.114 \mu \mathrm{m}$ (the wells shown with blue arrows) while the MBC was found to be $2.228,4.456$ and $4.456 \mu \mathrm{m}$ (the wells shown in black arrows) against the said organisms respectively. MIC was defined where the colour first changed sharply from pink to brick red colour and the MBC was defined where the brick red colour first intensified.

orange coloured signals which show the substantial interaction of quantum curcumin with the matrix materials. Panel 12C, a fluorogram, portrays the co-localization of CurQDs and the matrix for the region where a line is arbitrarily drawn for the stability assessment of the nature of co-localization (Fig. 12C). The unvarying linearity was observed for the signals in the fluorogram that revealed the stable association/interaction.

\section{Discussion}

The primary objective of the present study was the synthesis and the appraisal of antibacterial and antibiofilm potential of quantum curcumin (CurQDs) on pathogens especially involved in progression and aggravation of oral disease(s) such as chronic periodontitis ( $P$. gingivalis ATCC 33277, A. viscosus ATCC 29522 and $S$. mutans ATCC 25175). We further attempted to observe the inhibitory effects of quantum curcumin over $P$ gingivalis specific gingipains (Arg- and Lys-specific proteinases). Besides, we also evaluated the biocompatibility of quantum curcumin in detail.

Quantum dots (QDs) are the discrete class of fluorescent particles with smaller physical dimensions compared to the exciton Bohr radius. These QDs have high quantum efficiency, long-term photo-stability, narrow emission, and continuous absorption spectra. ${ }^{43}$ Excitation-emission profile reveals that it always emits the same light irrespective of excitation wavelength. This simply implies that a single emitted colour can be seen throughout by using single laser excitation source. This emitted wavelength can further be used for imaging owing to excellent photo-stability. ${ }^{\mathbf{4 4}}$ Our synthesized quantum curcumin was found to be green fluorescent and this property was exploited well in the confocal microscopy. No additional fluorescent tag was needed for the evaluation of its biological activity using CLSM or any other method that requires

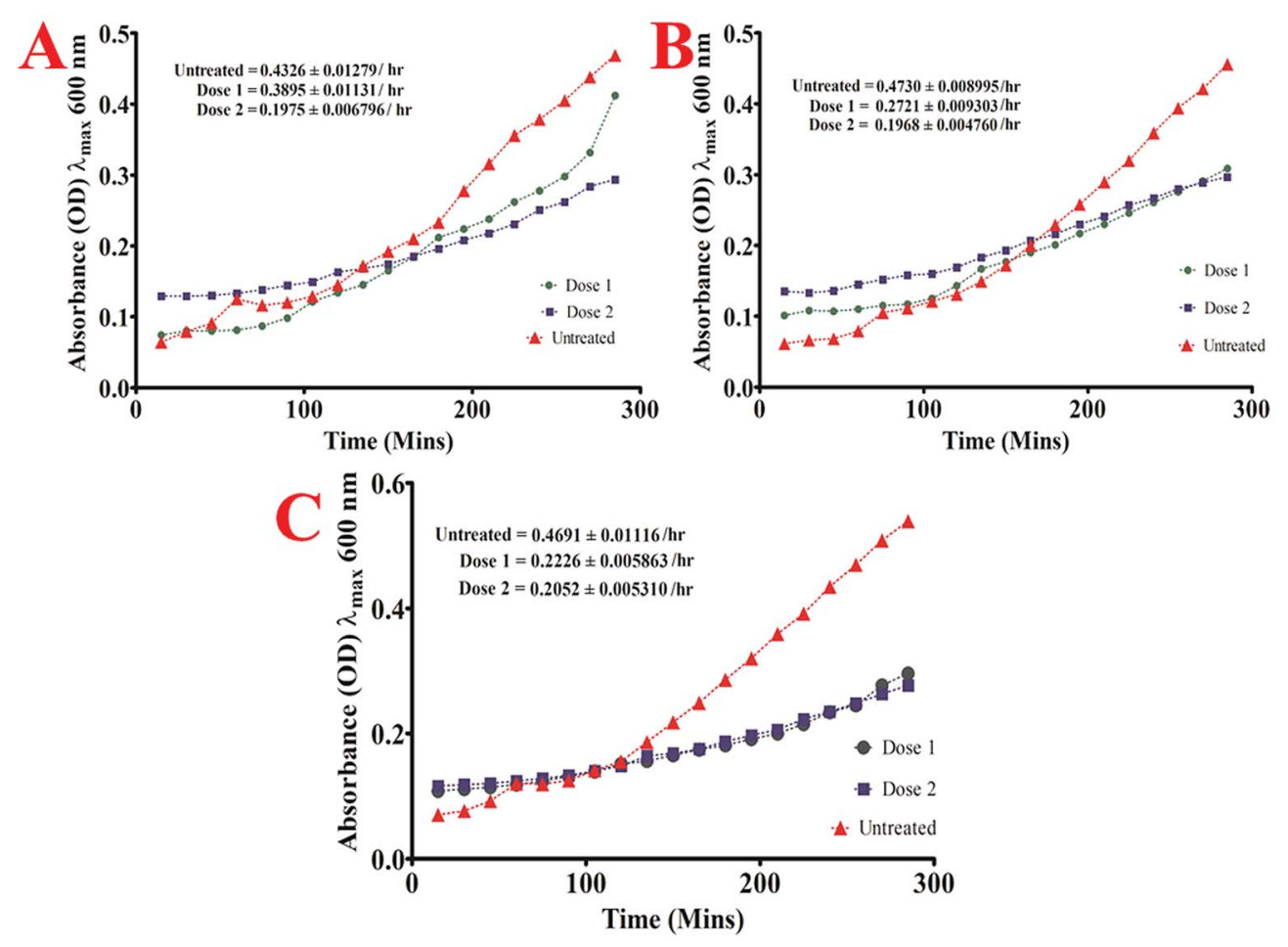

Fig. 8 Growth rate analysis curve of (A) P. gingivalis (ATCC 33277) (B) A. viscosus (ATCC 29522) and (C) S. mutans (ATCC 25175). 


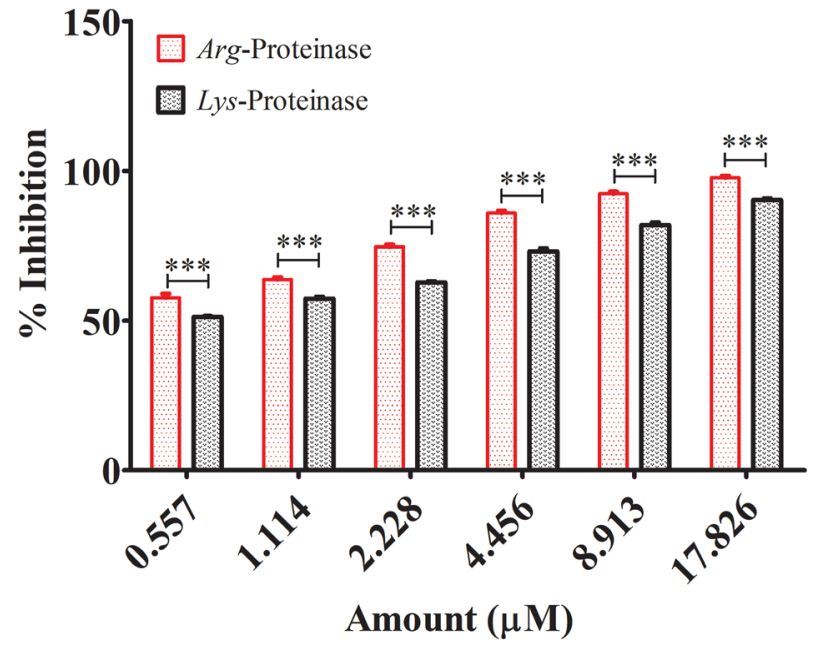

Fig. 9 Inhibitory effect of quantum curcumin on $P$. gingivalis gingipains (Arg- and Lys-proteinases). The inhibition percentage was found to be dose dependent with maximum inhibition of $98.7 \%$ and $89.4 \%$ respectively for Arg- and Lys-proteinases at the concentration of $17.826 \mu \mathrm{m}$. Of note at all concentrations quantum curcumin was found to be more effective in inhibiting Arg-proteinase compared to Lysproteinase.

fluorescent probing/tagging. In our present study, after synthesizing CurQDs as per protocol from our previous study, we analysed the QDs particle on some additional parameters such as X-ray photoelectron spectroscopy, X-ray diffraction analysis and NMR apart from the previously described parameters.

Essentially, biomedical applications of QDs require their high-quality and high aqueous solubility. Quantum dots could be made directly in water but they are polydisperse. They have either narrow available size ranges or wide size distribution. This obscures its use as imaging material in biological systems. ${ }^{4-47}$ But bestows an additional advantage in trickling down across the layers of biofilm matrices with assorted pore sizes. For imaging pursuits, monodisperse quantum dots can be produced from high-temperature organic solvent synthetic strategies possessing wide emission colours which may range from ultraviolet to near infrared $(300-2500 \mathrm{~nm})$ by simply tuning its size, composition and/or structure. However, these QDs are insoluble in water. ${ }^{48}$

QDs have unique physico-electro-optical properties due to the combination of innate material characteristics \& its dimensionality. Our PL and UV-vis profile is in consonance with the said characteristics. The rationale behind the stronger activity of quantum curcumin is related to the reduction in its particle size in the range of 0.5 to $7 \mathrm{~nm}$ (average size $3.5 \mathrm{~nm}$ ), which is far less than the size of native curcumin particles (average size $2350 \mathrm{~nm}$ ). This may be the reason for better penetration and interaction with the biofilm matrix and higher uptake by the bacterial cells.

The basic challenge of quantum dot synthesis is to control its uniform growth using stabilizers to avoid agglomeration or aggregation that may culminate into the formation of microcrystals. However, during our synthesis, when acetone dissolved curcumin was injected slowly at the rate of $0.2 \mathrm{ml} \mathrm{min}^{-1}$ in the aqueous phase at $75 \pm 5{ }^{\circ} \mathrm{C}$ with continuous ultra-sonication, the solubilized curcumin spread simultaneously with acetone with rapid volatilization. As acetone is miscible with water with density almost half of it, its rapid volatilization in presence of high energy sonication, resulted in sizing down of curcumin to quantum dot level, ruled out the need of addition of stabilizers to prevent conglomeration. The TEM profile revealed that the average size of the CurQDs was $3.5 \mathrm{~nm}$. The HR-TEM shows an interlayer spacing of $\sim 0.63 \mathrm{~nm}$ corresponding to the (002) plane of curcumin. The XRD data of quantum curcumin reveals number of peaks in the range of $2 \theta\left(10-40^{\circ}\right)$ implying its crystalline nature. XRD was used to verify the crystalline content of the drug present in the formulation. Surface characteristics and

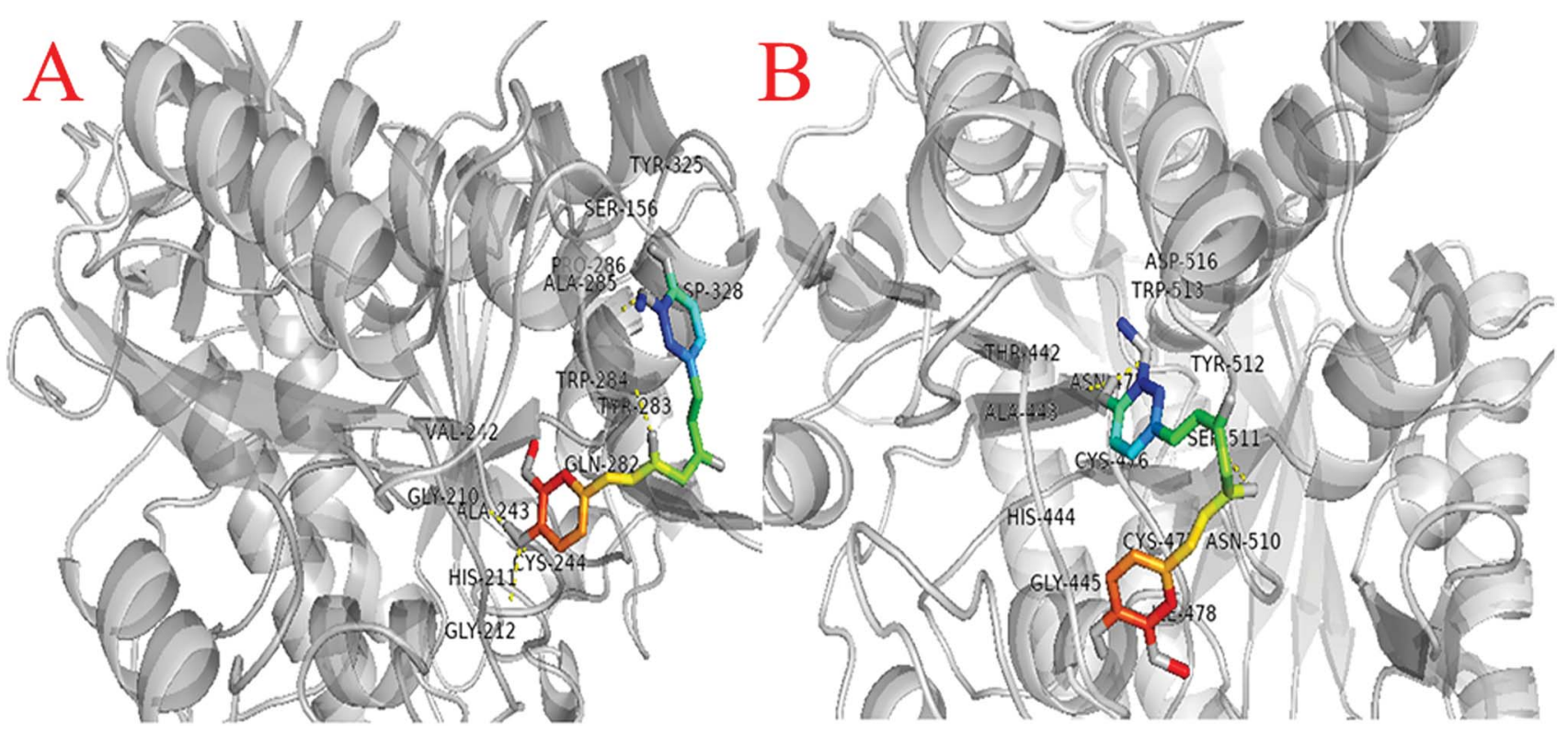

Fig. 10 (A) Interaction of curcumin with gingipain $\mathrm{R}(\mathrm{B})$ interaction of curcumin with gingipain $\mathrm{K}$. 
Table 3 Comparison of biofilm degradative activity of CurQDs $(\mu \mathrm{M})$ based on percent reduction in biofilm biomass in TCP assay

Bacterial strains Biofilm inhibition as \% decrease in biomass/matrix

Porphyromonas gingivalis, ATCC 33277

Actinomycetemcomitans viscosus, ATCC

97.43

91.29

88.77

Streptococcus mutans, ATCC 25175

Mixed biofilm, P. gingivalis, $S$. mutans

and $A$. viscosus together

Mixed biofilm, $S$. mutans $+A$. viscosus

then $P$. gingivalis

Effective conc. $(\mu \mathrm{M})$

93.28

81.65

17.826
圆 $\mathrm{AV}$

圆 SM

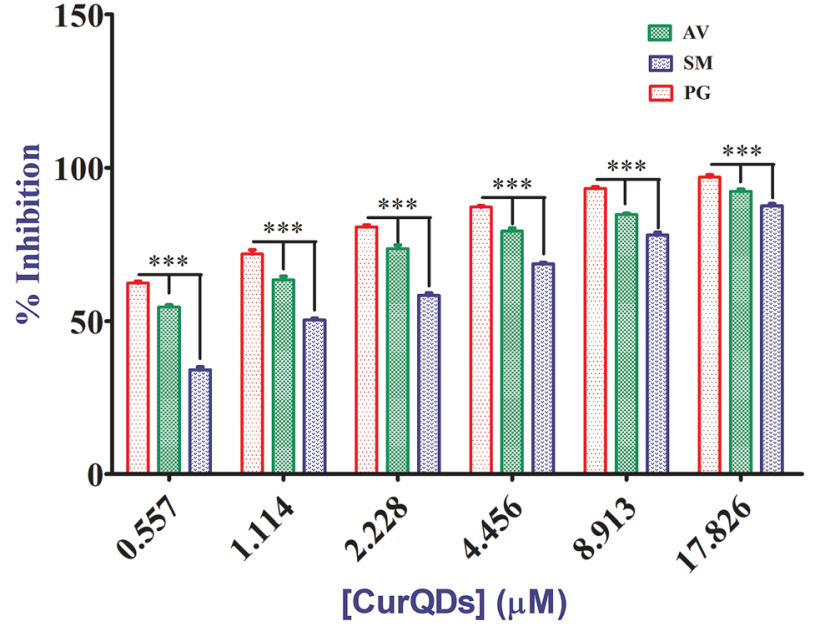

Fig. 11 Evaluation of the degradative effect of quantum curcumin on biofilm formation by TCP assay. The inhibition was concentration dependent in all the three bacteria. P. gingivalis biofilm was found to be more susceptible compared to those of $A$. viscosus and S. mutans.

charge of CurQDs were investigated by zeta potential analysis and was found to be $-25.6 \mathrm{mV}$. This value provides indirect evidence of the potential stability of the quantum curcumin. The UV-vis spectra showed three bands at $\sim 265,426$ and $512 \mathrm{~nm}$. A broad absorption band was obtained at $\sim 426 \mathrm{~nm}$ along with a shoulder at $\sim 512 \mathrm{~nm}$ extending to the visible region. The absorption band at $426 \mathrm{~nm}$ in the visible region can be assigned to low energy $\pi-\pi *$ transitions of curcumin in water arising possibly due to change in the tautomeric form of the keto-enol-enolate group. The chemistry of the synthesized quantum curcumin was further ascertained by using ${ }^{1} \mathrm{H}$ and ${ }^{13} \mathrm{C}$ NMR spectroscopy. Besides, Raman spectroscopy was also used to assess the phase variability and the structure of the quantum curcumin. The results clearly show the synthesis of curcumin quantum dots.

Various institutions across the globe have looked for its toxicity profile. Curcumin has been assessed by the Joint FAO/ WHO Expert Committee on Food Additives (JECFA) and the EU Scientific Committee for Food (SCF). ${ }^{49}$ The JECFA set an acceptable daily intake (ADI) value of $0-3 \mathrm{mg} \mathrm{kg}^{-1}$ body weight per day for curcumin in 2004. The ADI value of $3 \mathrm{mg} \mathrm{kg}^{-1}$ body weight per day was based on the NOAEL (no observed adverse effect level) of $250-320 \mathrm{mg} \mathrm{kg}^{-1}$ body weight per day. The SCF, on the other hand, has not made any specification for the ADI value of curcumin..$^{50}$ According to the directive 67/548/EWG as reported by Rimbach $e t$ al., curcumin neither poses a threat to man nor the environment. ${ }^{50}$ The JECFA evaluated four acute oral toxicity studies in mice and rats and found $\mathrm{LD}_{50}$ values of 2 to $10 \mathrm{~g} \mathrm{~kg}^{-1}$ body weight for mice and 5 to $10 \mathrm{~g} \mathrm{~kg}^{-1}$ body weight for rats. In the present study, the in vitro toxicity profiling was done in the range of 2-32 $\mu \mathrm{g} \mathrm{ml}^{-1}$ and it qualified as non-toxic on all the concentrations. ${ }^{49}$ Therefore, the quantum curcumin (CurQDs) in the present study was found significantly effective as both antibacterial and antibiofilm agent that too in the concentration as low as $0.089 \mu \mathrm{g} \mathrm{ml}^{-1}$ while it was found nontoxic even at the concentration of $1024 \mu \mathrm{g} \mathrm{ml}{ }^{-1}$ which is much below the maximum non-toxic threshold level as reported earlier.

To determine whether the synthesized CurQDs showed only anti-bacterial and antibiofilm efficacy without imparting any toxicity to healthy cells, its biocompatibility was evaluated. For this purpose, the morphology of Vero cells after treatment for $24 \mathrm{~h}$ of culture was monitored by phase contrast and fluorescence microscopy. Results clearly suggested that the Vero cells proliferated over the time forming a cell layer on the culture plate. Notably, the Vero cells displayed a more polygonal morphology upon CurQDs treatment which is the normal phenotype behavior of healthy Vero cells, suggesting that quantum curcumin restored/promoted Vero functionality.

The viability and proliferation rate of Vero cells were characterized by MTT assay, which was directly proportional to the optical density of the reaction product from the MTT working solution with live cells. As seen, clearly in Fig. S1, $\uparrow$ after 3 days, the viability was significantly higher indicating that quantum curcumin has enhanced the cell viability.

Periodontitis continues to be a major health concern, particularly amid people with poor oral hygiene. Its development and progression involve multifactorial cascades and to a larger extent, it is dynamic in terms of its regulation and socialization. ${ }^{7,8}$ The primary microbiological factor which is significantly responsible for the disease progression is the shift in the oral microflora. ${ }^{5}$ Virulence factors of $P$. gingivalis are diverse and can be broadly classified on functionality. For instance, while fimbriae, hemagglutinins, outer membrane proteins, vesicles, and gingipains are mainly involved in colonization and attachment, proteinases (Arg- and Lys-gingipains), 


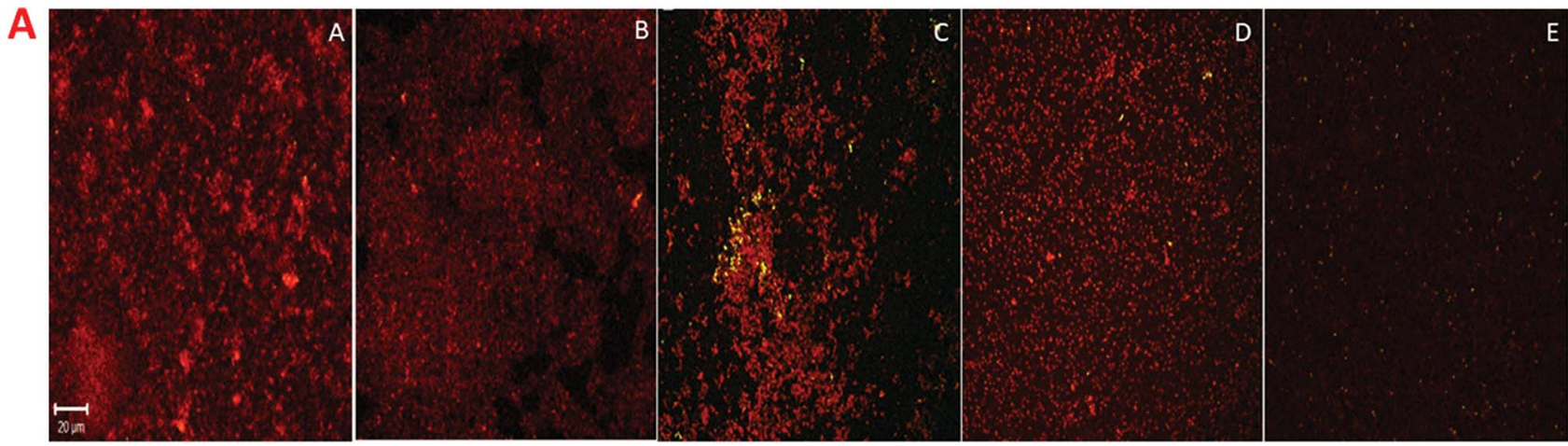

B
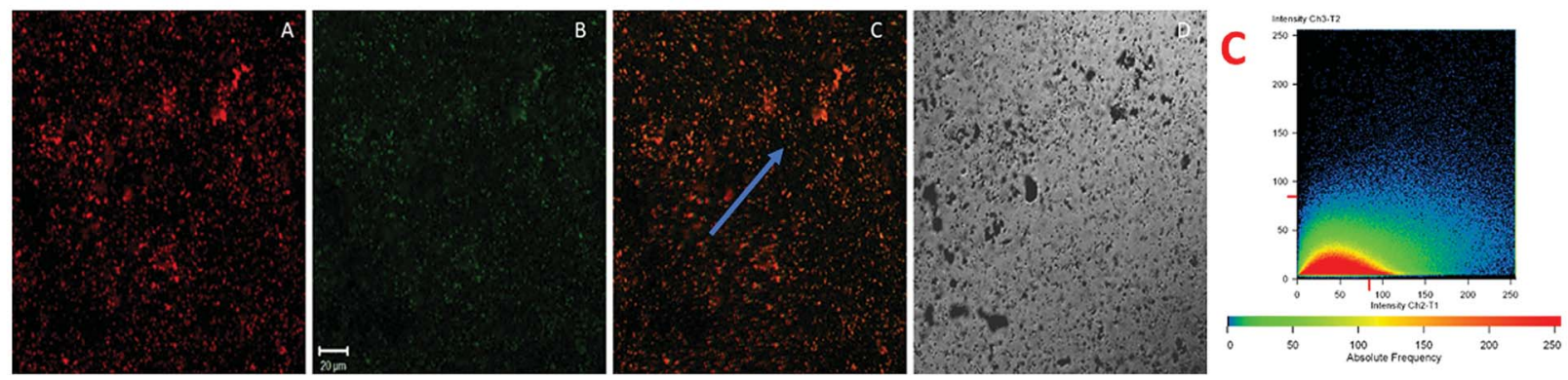

Fig. 12 The confocal micrographs of mixed biofilm matrix stained by tetramethyl-rhodamine isothiocyanate (TRITC) labeled concanavalin A (red) and treated with autofluorescent quantum curcumin (green). The square panels depict planar view looking down on the biofilm. (A) A-E extracellular red staining of the exopolysaccharide by Con A-TRITC seen on $72 \mathrm{~h}$ old mixed biofilm of $P$. gingivalis, A. viscosus, and S. mutans. Application of the TRITC labelled Con A resulted in the dense-cloudy appearance as seen in A(A) (the control lane). The initial exposure to 0.557 $\mu \mathrm{m}$ CurQDs increased the porosity of the biofilm matrix indicating the loosening of the matrix material ( $A(B))$. As the exposure concentration was increased to $17.826 \mu \mathrm{m}$, biofilm matrix disintegrated completely such that the individual planktonic cells can be seen scattered (B) selective study of the panel $D$ of a i.e. A(D). Panel A shows the Con A-TRITC labelled biofilm matrix material. Panel $B$ shows the drug distribution across the biofilm. Panel $C$ depicts the merged overlay of panels A and B. Panel D shows the phase contrast overlay. (C) A fluorogram showing the colocalization of TRITC-labeled concanavalin A (red) and quantum curcumin (green). Extracellular matrix sugars are stained red by Con A-TRITC while extracellular green staining is due to the drug. The intermediary yellow signals represent the co-localization of Con A-TRITC and quantum curcumin, indicating the strong interaction with the biofilm matrix. Note the linearity of the intensity on $x$-axis. The intensity of green signal is proportional to the red signal.

collagenase, fibrinolytic, keratinolytic, and other hydrolytic enzymes are involved in damaging host tissues.,13

The study of the effect of either form of curcumin (native and quantum) against periodontopathic bacteria has not received much ponderance. However, a recent study by Izui et al. reports the MIC of curcumin against $P$. gingivalis ATCC 33277 to be 15 $\mu \mathrm{g} \mathrm{ml}{ }^{-1}$. ${ }^{41}$ However, the MIC in the present study was found to be $1.114 \mathrm{mM}\left(0.41 \mu \mathrm{g} \mathrm{ml}{ }^{-1}\right)$, which is incongruous with the previous report. Interestingly, the MIC of quantum curcumin ranged from $0.557-8.913 \mu \mathrm{M}\left(0.205-3.28 \mu \mathrm{g} \mathrm{ml}^{-1}\right)$ in the present study. Socransky et al. suggested the strikingly significant role of $P$. gingivalis in periodontal disease. ${ }^{51}$ Therefore, the effect of CurQDs on the growth of $P$. gingivalis was investigated thoroughly wherein at significantly low concentrations $(0.557 \mu \mathrm{M})$ quantum curcumin exhibited the strong inhibitory effects. The same efficacy was noted against other cariogenic pathogens in this study namely $A$. viscosus and $S$. mutans.

Fimbriae and proteinases are two major virulent factors that significantly weigh in to the $P$. gingivalis pathogenesis., ${ }^{3,13}$ To date, four $P$ gingivalis proteinases are recognized serine, aspartate, thiol and metalloproteinase. Of these, the collagenases, aminopeptidases, and the trypsin-like proteinases are critical to $P$. gingivalis pathogenesis. The "thiol" proteases are "trypsinlike" enzymes those cleave polypeptides at the C-terminal after arginine or lysine residues and therefore named gingipain $\mathrm{R}$ and $\mathrm{K} .{ }^{52}$ Both the Arg-gingipain and the Lys-gingipain do not share any structural/sequence similarity with any of the other known cysteine proteinase. ${ }^{3}$ These potent non-fimbrial adhesins fervently bind to several extracellular matrix proteins like fibrinogen, fibronectin, and collagen type $\mathrm{V}$ etc. Gingipains are belligerent endopeptidases, capable of degrading serum and tissue-derived proteins. The protein fragments obtained after degradation are ultimately subjected to further digestion by diand tripeptidyl peptidases to release di- and tripeptides which are then taken up by $P$. gingivalis for its carbon and energy metabolism. ${ }^{14,15}$ Reports suggest that in densely populated biofilms, gingipains trim the cationic antimicrobial peptides to enable the bacterial survival. Degradation of cationic antimicrobial peptides obscures the neutralization of lipopolysaccharides, which may lead to intensified and unremitting production of pro inflammatory cytokines. ${ }^{7}$ Gingipains degrade different components of complement as well. ${ }^{3}$ In this study, we, therefore, investigated the effects of quantum curcumin on $P$. gingivalis Arg- and Lys-specific proteinases activities. Earlier polyphenol(s) and catechins(s) derivatives have been reported to inhibit Arg- and Lys-specific proteinases of $P$. gingivalis. ${ }^{53-55}$ In the present study, 58.2\% reduction in Arg-specific proteinase activity was observed at $0.557 \mu \mathrm{M}$ CurQDs while $98.7 \%$ of 
reduction was seen at the concentration of $17.826 \mu \mathrm{M}$ in both ATCC 33277 and clinical isolates of $P$. gingivalis. The similar trend was seen over Lys-specific proteinase activities with $51.4 \%$ and $89.4 \%$ reduction upon administration with $0.557 \mu \mathrm{M}$ and 17.826 $\mu \mathrm{M}$ CurQDs concentrations. The results obtained here was then investigated by in silico docking analysis by AutoDock. The thermodynamic profile of the interaction of curcumin with gingipains $\mathrm{R}$ and $\mathrm{K}$ indicated that the binding process was characterized by large exothermic enthalpies $(-7.01$ and -7.02 cal $\mathrm{mol}^{-1}$ ). Besides, the inhibition constant was found to be $7.24 \mu \mathrm{M}$ and 7.1 $\mu \mathrm{M}$ against gingipains $\mathrm{R}$ and $\mathrm{K}$ respectively. In the present study, curcumin was found adopting conformations suitable for maximizing interactions with the gingipains. This may be due to its novel structural geometry and chemistry which include two hydrophobic phenyl domains connected by a flexible methylene linker along with keto-enol tautomerism which provides a strong and directed electrostatic interaction to increase favorable binding free energy.

Recently, the effect of native curcumin on mature, multispecies biofilm was also reported wherein the multispecies biofilm was allowed to mature for 7 days and then treated with curcumin for $24 \mathrm{~h}$. After treatment, the outré-structural changes were observed using scanning electron microscopy. ${ }^{56,57}$ Curcumin-treated biofilms displayed significantly reduced metabolic activity and no visible extracellular matrix. Although the previous study investigated the effects of curcumin on matured biofilms, the current study investigates the effect of curcumin on the early as well as the late stages of biofilm formed by $P$. gingivalis with $S$. mutans and $A$. viscosus, mimicking the in vivo condition of biofilm associated lesion of periodontitis.

We observed when all the three bacteria were grown concurrently and then the drug was administered, the effect of the drug was maximum, and at $8.913 \mu \mathrm{M}$ concentration, biofilm was completely suppressed within $90 \mathrm{~min}$. The said observation was in consonance with the report which ascertains the involvement of $P$. gingivalis FimA and streptococcal cell surface glyceraldehyde-3-phosphate dehydrogenase (GAPDH) in the early stages of biofilm formation. ${ }^{58}$ Therefore, it can be conjectured that quantum curcumin binds with high affinity to the $P$. gingivalis FimA which subsequently inhibits its binding to the streptococcal GAPDH, culminating in the suppression of the biofilm. Moreover, in accordance with other reports, it may also inhibit auto-aggregation and interaction of FimA with salivary proteins, resulting in suppression of $P$. gingivalis biofilm formation. However, we cannot confirm whether the observed inhibition is owing to the different mechanism(s) or simply it represents multifactorial selection of targets depending upon the site, ending up in biofilm inhibition. However, we hypothesized the killing action of quantum curcumin by membrane permeabilization and subsequent lysis.

The TCP assay results and our hypothesis pertaining to the mode of action was further validated by CLSM wherein P. gingivalis (late colonizer of dental biofilm) was added to antecedently formed biofilm of $S$. mutans and A. viscosus (facilitator). We found CurQDs significantly effective in degradation of the biofilm matrix at the dose as low as $8.913 \mu \mathrm{M}\left(3.28 \mu \mathrm{g} \mathrm{ml}^{-1}\right)$. The result revealed the interaction(s) between quantum curcumin and the biofilm matrix which eventually culminated in the loosening and ultimately degradation of the biofilm in the concentration dependent manner. Quantum curcumin is the green fluorescent moiety while concanavalin A (Con A), labelled with tetramethyl-rhodamine isothiocyanate (TRITC) exhibits red fluorescence. Con A-TRITC binds with matrix sugars and hence gives a gross approximation related to biofilm biomass. The colocalization map unfolds the juxtapositioning of Con ATRITC and the quantum curcumin which is the indicative of its higher affinity for the biofilm matrix material. Accurate colocalization analysis requires distinct fluorescence emission spectra. Both Con A-TRITC and quantum curcumin colours are easily distinguishable and therefore yielded clear fluorogram with minimal bleed-through.

Reports pertaining to the maintenance of periodontal health using numerous natural products/phyto-extracts/plant secondary metabolites are in abundance. They were screened for their potential to inhibit periodontitis. ${ }^{53-57,59,60}$ For instance, extracts from $E$. globules leaf, exhibited the antibacterial activity with MIC values of 1-10 $\mu \mathrm{g} \mathrm{ml}^{-1}$ against $P$. gingivalis and $T$. denticola, and was found to inhibit $P$. gingivalis Arg- and Lysspecific proteinase activities at $50-100 \mu \mathrm{g} \mathrm{ml}{ }^{-1} .^{55}$ Similarly, another controlled study showed that chewing gum containing eucalyptus extracts significantly inhibited the plaque formation and gingival inflammation. ${ }^{53}$ The MIC of CurQDs was some 244 times lower $\left(1.114 \mu \mathrm{M}, 0.41 \mu \mathrm{g} \mathrm{ml}^{-1}\right)$ than that of all testified plant secondary metabolites against $P$. gingivalis. Besides, CurQDs also inhibited the growth of other anaerobes like $A$. viscosus as well and other cariogenic bacteria like $S$. mutans whereas other plant secondary metabolites had insignificant effects on the same. Recent reports suggest that green tea (Camellia sinensis) polyphenols, particularly epigallocatechin gallate, inhibited the growth of $P$. gingivalis at concentrations of 250-500 $\mu \mathrm{g} \mathrm{ml}^{-1}$ and $50 \mathrm{mg} \mathrm{ml}{ }^{-1}$. $^{61,62}$ It is therefore, obvious that compared to the quantum curcumin the efficacy of the said phytochemicals are significantly compromised.

Recently, therapeutic efficacy of curcumin for the treatment of aggravated and chronic periodontitis was evaluated in a pilot study. In the study, it found that the patients who underwent scaling and root planing, followed by using curcumin mouthwash $(20 \%)$ for 21 days, showed significant improvement in the gingival inflammation than those who underwent only scaling and root planing. However, they found insignificant difference in their plaque indices. ${ }^{63}$

\section{Conclusion}

The molecule curcumin, the most active polyphenol present in curcuma, owing to its high hydropathy index and instability has not been able to justify its role as frontline drug modality in the treatment of infectious and non-infectious diseases. The results of the current study indicate that quantum curcumin not only inhibited the growth of various periodontopathic bacteria but also exhibited potent antibiofilm activities against mixed biofilm formed by $P$. gingivalis, A. viscosus, and S. mutans. Being an asaccharolytic bacterium, $P$. gingivalis solely relies for its carbon 
and energy sources from proteins, which proves the inevitable role of these gingipains $\mathrm{R}$ and $\mathrm{K}$ for the growth and multiplication in the host that help in continuing the vicious life cycle leading to the proliferation and aggravation in the lesion of chronic periodontitis. Therefore, in this context, the activity of quantum curcumin against $P$. gingivalis specific Arg- and Lysproteinase indicates its usefulness as first-line therapeutic modality. The bioassay utilized herein for evaluating inhibitors of $P$. gingivalis specific Arg- and Lys-specific proteinases may be used in future in screening of potential drugs candidates against such pathogens. However, for pharmacological investigations one may utilize appropriate animal models such as nonhuman primates (like rhesus monkeys (Macaca mulatta), cynomolgus monkeys (Macaca fascicularis), and baboons (Papio anubis)), miniature pigs (Minnesota miniature pig), dogs, ferrets (Mustela putorius) and rodents (rice rat (Oryzomys palustris), baker mouse) to substantiate the role of quantum curcumin in the management of chronic periodontitis. In all, these results add to the considerable body of evidence of antibacterial, antivirulence, antibiofilm activities of quantum curcumin over $P$. gingivalis.

\section{Author contributions}

A. K. S. and P. P. conceived, designed and analyzed results of the study. A. K. S. and S. Y. designed the cultivation experiments, performed susceptibility experiments, bacterial growth rate analysis, gingipains inhibition assay along with biofilm degradation assay. A. K. S., Z. F., P. A. performed experiments on synthesis, physical characterizations and analyzed data. A. K. S., M. B., M. K. G. performed confocal microcopy experiments and analyzed the data. A. K. S., Z. F., P. A., K. N., and P. K. N. performed toxicity assay while A. K. S. and KS performed and analyzed results with flow cytometry. A. K. S. wrote the manuscript which was endorsed by all the co-authors.

\section{Conflicts of interest}

There are no conflicts to declare.

\section{Acknowledgements}

We sincerely acknowledge the financial support from the Department of Science and Technology, Government of India [DST project (DST/TSG/NTS/2013/47) sanctioned to MB, and PP, contingency grant offered to AKS as JRF (2061430918 vide 22/06/ 2014(i) EU-V) by University Grants Commission, New Delhi and DST-PURSE grant sanctioned to Department of Microbiology, IMS, BHU.

\section{References}

1 R. C. Page and K. S. Kornman, The pathogenesis of human periodontitis: an introduction, Periodontol. 2000, 1997, 14, 9-11.

2 R. C. Page, S. Offenbacher, H. E. Schroeder, G. J. Seymour and K. S. Kornman, Advances in the pathogenesis of periodontitis: summary of developments, clinical implications and future directions, Periodontol. 2000, 1997, 14, 216-248.

3 K. Y. How, K. P. Song and K. G. Chan, Porphyromonas gingivalis: an overview of periodontopathic pathogen below the gum line, Front. Microbiol., 2016, 7, 53.

4 P. E. Petersen and H. Ogawa, The global burden of periodontal disease: towards integration with chronic disease prevention and control, Periodontol. 2000, 2012, 60, 15-39.

5 A. B. Berezow and R. P. Darveau, Microbial shift and periodontitis, Periodontol. 2000, 2011, 55, 36-47.

6 M. Nakayama and N. Ohara, Molecular mechanisms of Porphyromonas gingivalis-host cell interaction on periodontal diseases, Jpn. Dent. Sci. Rev., 2017, 134-140.

7 G. Hajishengallis, Periodontitis: from microbial immune subversion to systemic inflammation, Nat. Rev. Immunol., 2015, 15, 30 .

8 G. Hajishengallis, Immunomicrobial pathogenesis of periodontitis: keystones, pathobionts, and host response, Trends Immunol., 2014, 35, 3-11.

9 P. M. Bartold and T. E. Van Dyke, Periodontitis: a hostmediated disruption of microbial homeostasis. Unlearning learned concepts, Periodontol. 2000, 2013, 62, 203-217.

10 A. C. R. Tanner, C. Haffer, G. T. Bratthall, R. A. Visconti and S. S. Socransky, A study of the bacteria associated with advancing periodontitis in man, J. Clin. Periodontol., 1979, 6, 278-307.

11 J. Mysak, S. Podzimek, P. Sommerova, Y. Lyuya-Mi, J. Bartova, T. Janatova, et al., Porphyromonas gingivalis: major periodontopathic pathogen overview, J. Immunol. Res., 2014, 2014, 1-8.

12 H. K. Datta, W. F. Ng, J. A. Walker, S. P. Tuck and S. S. Varanasi, The cell biology of bone metabolism, J. Clin. Pathol., 2008, 61, 577-587.

13 C. W. Cutler, J. R. Kalmar and C. A. Genco, Pathogenic strategies of the oral anaerobe, Porphyromonas gingivalis, Trends Microbiol., 1995, 3, 45-51.

14 J. Travis, R. Pike, T. Imamura and J. Potempa, Porphyromonas gingivalis proteinases as virulence factors in the development of periodontitis, J. Periodontal Res., 1997, 32, 120-125.

15 J. Potempa, A. Sroka, T. Imamura and J. Travis, Gingipains, the major cysteine proteinases and virulence factors of Porphyromonas gingivalis: structure, function and assembly of multidomain protein complexes, Curr. Protein Pept. Sci., 2003, 4, 397-407.

16 T. Bengtsson, A. Khalaf and H. Khalaf, Secreted gingipains from Porphyromonas gingivalis colonies exert potent immunomodulatory effects on human gingival fibroblasts, Microbiol. Res., 2015, 178, 18-26.

17 I. de Diego, F. Veillard, M. Sztukowska, T. Guevara, B. Potempa, A. Pomowski, et al., Structure and mechanism of cysteine peptidase Kgp, a major virulence factor of Porphyromonas gingivalis in periodontitis, J. Biol. Chem., 2014, DOI: $10.1074 /$ jbc.M114.602052. 
18 A. D. Haffajee, M. A. Cugini, S. Dibart, C. Smith, R. L. Kent Jr and S. S. Socransky, Clinical and microbiological features of subjects with adult periodontitis who responded poorly to scaling and root planing, J. Clin. Periodontol., 1997, 24, 767-776.

19 L. Sbordone, L. Ramaglia, E. Gulletta and V. Iacono, Recolonization of the subgingival microflora after scaling and root planing in human periodontitis, J. Periodontol., 1990, 61, 579-584.

20 D. Herrera, M. Sanz, S. Jepsen, I. Needleman and S. Roldán, A systematic review on the effect of systemic antimicrobials as an adjunct to scaling and root planing in periodontitis patients, J. Clin. Periodontol., 2002, 29, 136-159.

21 A. P. V. Colombo, S. K. Boches, S. L. Cotton, J. M. Goodson, R. Kent, A. D. Haffajee, et al., Comparisons of subgingival microbial profiles of refractory periodontitis, severe periodontitis, and periodontal health using the human oral microbe identification microarray, J. Periodontol., 2009, 80, 1421-1432.

22 J. G. Caton, S. G. Ciancio, T. M. Blieden, M. Bradshaw, R. J. Crout, A. F. Hefti, et al., Treatment with subantimicrobial dose doxycycline improves the efficacy of scaling and root planing in patients with adult periodontitis, J. Periodontol., 2000, 71, 521-532.

23 P. D. Marsh, D. A. Head and D. A. Devine, Prospects of oral disease control in the future-an opinion, J. Oral Microbiol., 2014, 6, 26176.

24 J. Frias, E. Olle and M. Alsina, Periodontal pathogens produce quorum sensing signal molecules, Infect. Immun., 2001, 69, 3431-3434.

25 A. K. Singh, P. Prakash, R. Singh, N. Nandy, Z. Firdaus, M. Bansal, et al., Curcumin Quantum Dots Mediated Degradation of Bacterial Biofilms, Front. Microbiol., 2017, 8, 1517.

26 R. De, P. Kundu, S. Swarnakar, T. Ramamurthy, A. Chowdhury, G. B. Nair, et al., Antimicrobial activity of curcumin against Helicobacter pylori isolates from India and during infections in mice, Antimicrob. Agents Chemother., 2009, 53, 1592-1597.

27 W. Jianhua and W. Hai, Antifungal susceptibility analysis of berberine, baicalin, eugenol and curcumin on Candida albicans, J. Med. Coll. PLA, 2009, 24, 142-147.

28 E. Marini, M. Di Giulio, G. Magi, S. Di Lodovico, M. E. Cimarelli, A. Brenciani, et al., Curcumin, an antibiotic resistance breaker against a multiresistant clinical isolate of Mycobacterium abscessus, Phyther. Res., 2018, 32, 488-495.

29 B. Wachter, M. Syrowatka, A. Obwaller and J. Walochnik, In vitro efficacy of curcumin on Trichomonas vaginalis, Wien. Klin. Wochenschr., 2014, 126, 32-36.

$30 \mathrm{P}$. $\mathrm{Hu}, \mathrm{P}$. Huang and $\mathrm{M}$. W. Chen, Curcumin reduces Streptococcus mutans biofilm formation by inhibiting sortase A activity, Arch. Oral Biol., 2013, 58, 1343-1348.

31 J. Song, B. Choi, E. J. Jin, Y. Yoon and K. H. Choi, Curcumin suppresses Streptococcus mutans adherence to human tooth surfaces and extracellular matrix proteins, Eur. J. Clin.
Microbiol. Infect. Dis., 2012, 31, 1347-1352, DOI: 10.1007/ s10096-011-1448-y.

32 S.-H. Mun, S.-B. Kim, R. Kong, J.-G. Choi, Y.-C. Kim, D.-W. Shin, et al., Curcumin Reverse Methicillin Resistance in Staphylococcus aureus, Molecules, 2014, 19, 18283-18295, DOI: 10.3390/molecules191118283.

33 B. R. K. Bhawana, H. S. Buttar, V. K. Jain and N. Jain, Curcumin nanoparticles: preparation, characterization, and antimicrobial study, J. Agric. Food Chem., 2011, 59, 2056-2061, DOI: 10.1021/jf104402t.

34 P. Tyagi, M. Singh, H. Kumari, A. Kumari and K. Mukhopadhyay, Bactericidal activity of curcumin $I$ is associated with damaging of bacterial membrane, PLOS One, 2015, 10, 1-15, DOI: 10.1371/journal.pone.0121313.

35 H. K. Syed, M. A. Iqbal, R. A. Haque and K.-K. Peh, Synthesis, characterization and antibacterial activity of a curcuminsilver(I) complex, J. Coord. Chem., 2015, 68, 1088-1100, DOI: 10.1080/00958972.2014.1003051.

36 O. Naksuriya, S. Okonogi, R. M. Schiffelers and W. E. Hennink, Curcumin nanoformulations: a review of pharmaceutical properties and preclinical studies and clinical data related to cancer treatment, Biomaterials, 2014, 35, 3365-3383, DOI: 10.1016/ j.biomaterials.2013.12.090.

37 Y. Liu, Y. Cai, X. Jiang, J. Wu and X. Le, Molecular interactions, characterization and antimicrobial activity of curcumin-chitosan blend films, Food Hydrocolloids, 2015, 52, 564-572, DOI: 10.1016/j.foodhyd.2015.08.005.

38 R. Feng, Z. Song and G. Zhai, Preparation and in vivo pharmacokinetics of curcumin-loaded PCL-PEG-PCL triblock copolymeric nanoparticles, Int. J. Nanomed., 2012, 7, 4089-4098, DOI: 10.2147/IJN.S33607.

39 J. N. Eloff, A sensitive and quick microplate method to determine the minimal inhibitory concentration of plant extracts for bacteria, Planta Med., 1998, 64, 711-713.

40 R. Pike, W. McGraw, J. Potempa and J. Travis, Lysine-and arginine-specific proteinases from Porphyromonas gingivalis. Isolation, characterization, and evidence for the existence of complexes with hemagglutinins, J. Biol. Chem., 1994, 269, 406-411.

41 S. Izui, S. Sekine, K. Maeda, M. Kuboniwa, A. Takada, A. Amano, et al., Antibacterial activity of curcumin against periodontopathic bacteria, J. Periodontol., 2016, 87, 83-90.

42 A. K. Singh, P. Prakash, A. Achra, G. P. Singh, A. Das and R. K. Singh, Standardization and classification of in vitro biofilm formation by clinical isolates of Staphylococcus aureus, J. Global Infect. Dis., 2017, 9, 93.

43 Y. Wang and L. Chen, Quantum dots, lighting up the research and development of nanomedicine, Nanomedicine, 2011, 7, 385-402, DOI: 10.1016/j.nano.2010.12.006.

44 X. Michalet, L. a Bentolila, J. M. Tsay and S. Doose, Quantum Dots for Live Cells in vivo Imaging, and Diagnostics, Science, 2005, 307, 538-544, DOI: 10.1126/science.1104274.

45 K. Sun, M. Vasudev, H.-S. Jung, J. Yang, A. Kar, Y. Li, et al., Applications of colloidal quantum dots, Microelectron. J., 2009, 40, 644-649, DOI: 10.1016/j.mejo.2008.06.033. 
46 T. Jamieson, R. Bakhshi, D. Petrova, R. Pocock, M. Imani and A. M. Seifalian, Biological applications of quantum dots, Biomaterials, 2007, 28, 4717-4732, DOI: 10.1016/ j.biomaterials.2007.07.014.

47 R. J. Byers and E. R. Hitchman, Quantum dots brighten biological imaging, Prog. Histochem. Cytochem., 2011, 45, 201-237, DOI: 10.1016/j.proghi.2010.11.001.

48 W. W. Yu, E. Chang, R. Drezek and V. L. Colvin, Watersoluble quantum dots for biomedical applications, Biochem. Biophys. Res. Commun., 2006, 348, 781-786, DOI: 10.1016/j.bbrc.2006.07.160.

49 E. F. S. Authority, Refined exposure assessment for curcumin (E 100), EFSA J., 2014, 12, 3876.

50 T. Esatbeyoglu, P. Huebbe, I. M. A. Ernst, D. Chin, A. E. Wagner and G. Rimbach, Curcumin-from molecule to biological function, Angew. Chem., Int. Ed., 2012, 51, 53085332, DOI: 10.1002/anie.201107724.

51 S. S. Socransky and A. D. Haffajee, Evidence of bacterial etiology: a historical perspective, Periodontol. 2000, 1994, 5, 7-25.

52 S. C. Holt, L. Kesavalu, S. Walker and C. A. Genco, Virulence factors of Porphyromonas gingivalis, Periodontol. 2000, 1999, 20, 168-238.

53 H. Nagata, Y. Inagaki, M. Tanaka, M. Ojima, K. Kataoka, M. Kuboniwa, et al., Effect of eucalyptus extract chewing gum on periodontal health: a double-masked, randomized trial, J. Periodontol., 2008, 79, 1378-1385.

54 H. Nagata, Y. Inagaki, Y. Yamamoto, K. Maeda, K. Kataoka, K. Osawa, et al., Inhibitory effects of macrocarpals on the biological activity of Porphyromonas gingivalis and other periodontopathic bacteria, Oral Microbiol. Immunol., 2006, 21, 159-163.

55 K. Takahashi, M. Fukazawa, H. Motohira, K. Ochiai, H. Nishikawa and T. Miyata, A pilot study on antiplaque effects of mastic chewing gum in the oral cavity, $J$. Periodontol., 2003, 74, 501-505.

56 C. C. C. Quishida, E. G. D. O. Mima, J. H. Jorge, C. E. Vergani, V. S. Bagnato and A. C. Pavarina, Photodynamic inactivation of a multispecies biofilm using curcumin and LED light, Lasers Med. Sci., 2016, 31, 997-1009.

57 N. C. Araújo, C. R. Fontana, V. S. Bagnato and M. E. M. Gerbi, Photodynamic effects of curcumin against cariogenic pathogens, Photomed. Laser Surg., 2012, 30, 393-399.

58 K. Maeda, H. Nagata, A. Nonaka, K. Kataoka, M. Tanaka and S. Shizukuishi, Oral streptococcal glyceraldehyde-3phosphate dehydrogenase mediates interaction with Porphyromonas gingivalis fimbriae, Microbes Infect., 2004, 6, 1163-1170.

59 M. Shahzad, E. Millhouse, S. Culshaw, C. A. Edwards, G. Ramage and E. Combet, Selected dietary (poly) phenols inhibit periodontal pathogen growth and biofilm formation, Food Funct., 2015, 6, 719-729.

60 N. C. Araújo, C. R. Fontana, M. E. M. Gerbi and V. S. Bagnato, Overall-mouth disinfection by photodynamic therapy using curcumin, Photomed. Laser Surg., 2012, 30, 96-101.

61 A. Araghizadeh, J. Kohanteb and M. M. Fani, Inhibitory activity of green tea (Camellia sinensis) extract on some clinically isolated cariogenic and periodontopathic bacteria, Med. Princ. Pract., 2013, 22, 368-372.

62 S. Sakanaka, M. Aizawa, M. Kim and T. Yamamoto, Inhibitory effects of green tea polyphenols on growth and cellular adherence of an oral bacterium, Porphyromonas gingivalis, Biosci., Biotechnol., Biochem., 1996, 60, 745-749.

63 S. Muglikar, K. C. Patil, S. Shivswami and R. Hegde, Efficacy of curcumin in the treatment of chronic gingivitis: a pilot study, Oral Health Prev. Dent., 2013, 11, 81-86. 